\title{
Environmental taxation: The impact of carbon tax policy commitment on technology choice and social welfare
}

\author{
Erica Rustico
}

\author{
A thesis \\ presented to the University of Waterloo \\ in fulfillment of the \\ thesis requirement for the degree of \\ Master of Applied Science \\ in \\ Management Sciences
}

Waterloo, Ontario, Canada, 2020

(C) Erica Rustico 2020 


\section{Author's Declaration}

I hereby declare that I am the sole author of this thesis. This is a true copy of the thesis, including any required final revisions, as accepted by my examiners.

I understand that my thesis may be made electronically available to the public. 


\begin{abstract}
Motivated by multiple real-world settings, we determine a social welfare-maximizing regulator's tax policies that induce a profit-maximizing polluting firm to make green technology choices. Using a game-theoretic approach we compare the optimal tax and social welfare over two periods under two scenarios: (1) a regulator committing to a tax level for both periods at the beginning of the first period; 2 ) a regulator who sets the same tax at the beginning of each period without disclosing this information to the firm (i.e. the firm is not aware of the second period tax in the first period). We find that regulators can achieve a higher social welfare when two-period commitments are made. Moreover, the outcomes in the commitment policy are less sensitive to small deviations in the optimal tax level.
\end{abstract}




\section{Acknowledgements}

I would like to express my sincere gratitude to my supervisor, Dr. Stan Dimitrov, for his guidance and support during this project. His expertise, patience, and encouragement made this project possible.

I would also like to thank my readers, Dr. Zhao and Dr. Elhedhli, for their helpful comments.

Finally, to my loving friends, family, and partner Ian: thank you for everything. 


\section{Table of Contents}

List of Figures $\quad$ vii

List of Tables $\quad$ viii

1 Introduction $\quad 1$

2 Related Work $\quad 4$

$\begin{array}{lll}3 & \text { Model Formulation } & 7\end{array}$

3.1 Firm's Decision Model . . . . . . . . . . . . . . . . 7

3.2 Regulator's Decision Model . . . . . . . . . . . . . . . . . . 10

3.3 Game Dynamics . . . . . . . . . . . . . . . . . . 11

4 Model Analysis $\quad 14$

4.1 The case of no regulator commitment . . . . . . . . . . . . . . . 14

4.1 .1 First Period . . . . . . . . . . . . . . . 15

4.1.2 Second Period . . . . . . . . . . . . . . . 17

4.2 The case of regulator commitment . . . . . . . . . . . . . . . 19

4.3 Comparing the case of no commitment and commitment . . . . . . . . 21

5 Numerical Examples $\quad 25$

5.1 Comparing the case of no commitment and commitment . . . . . . . . 25

5.2 Sensitivity of the optimal tax level . . . . . . . . . . . . . . . 30 
6 Discussion $\quad 38$

6.1 Theoretical Insights . . . . . . . . . . . . . . . . . . 38

6.2 Managerial Insights . . . . . . . . . . . . . . . . . . . . 40

7 Conclusion $\quad 42$

$\begin{array}{ll}\text { References } & 44\end{array}$

$\begin{array}{lc}\text { APPENDICES } & 48\end{array}$ 


\section{List of Figures}

3.1 Game dynamics. Top (red) outlines game dynamics in the no commitment case, bottom (green) outlines game dynamics in the commitment case. . . .

5.1 First period profit with no regulator commitment when the dirty (red) or green (green) technology is selected . . . . . . . . . . . . . .

5.2 Second period profit with no regulator commitment given the firm's technology choice in both periods . . . . . . . . . . . . . . . .

5.3 Total profit of the firm with regulator commitment given the firm's technology choice in both periods . . . . . . . . . . . . . . . . . . . . 28

5.4 Comparing the social welfare in the no commitment and commitment case, with $\epsilon=0.6$ (Example 1(a)) . . . . . . . . . . . . . . . . . . .

5.5 Comparing the social welfare in the no commitment and commitment case,

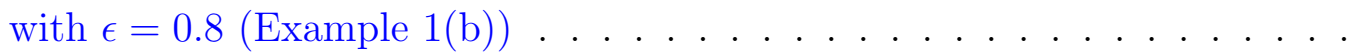

5.6 Comparing the social welfare in the no commitment and commitment case, with $\epsilon=1.1$ (Example 1(c)) . . . . . . . . . . . . . . . . . 


\section{List of Tables}

3.1 Main Notations . . . . . . . . . . . . . . . . 8

5.1 Summary of results at the optimal firm and regulator decisions (more favourable outcomes are shown in green) . . . . . . . . . . . . . 34

5.2 Summary of Results, $\epsilon=0.8$, just below the optimal tax, $t^{*}-\kappa$, where $\kappa=0.001 \ldots \ldots \ldots \ldots \ldots$

5.3 Summary of Results, $\epsilon=1.1$, just below the optimal tax, $t^{*}-\kappa$, where $\kappa=0.001 \ldots \ldots \ldots \ldots \ldots \ldots$ 


\section{Chapter 1}

\section{Introduction}

Many governments utilize environmental policies to regulate greenhouse gas emissions in an effort to combat the negative impacts of climate change. Some examples of popular environmental policies are subsidies, feed-in-tariffs, and carbon taxes, which are used to either incentivize the transition to a greener economy, or disincentivize the emissions of greenhouse gases. Many governments have successfully reduced their emissions by implementing environmental policies. For example, British Columbia's carbon tax, introduced in 2008, required fuel-producing firms to pay a tax per unit of carbon emissions (Yamazaki, 2017). In a review of the success of the BC carbon tax by Murray and Rivers (2015), simulations and empirical models suggest that the carbon tax reduced emissions in British Columbia by $5-15 \%$, with negligible effects on the economy.

However, not all environmental policies are successful. For example, in 2009, the government of Ontario, Canada signed a feed-in-tariff agreement to guarantee a price on wind energy in order to encourage the development of the wind energy sector (Yatchew and Baziliauskas, 2011). In response, wpd, a German company that finances wind projects around the world, began construction of the White Pines Wind Farm project (Global News, 2019). After construction had already started, the Ontario government passed the White Pines Termination Act, that cancelled the feed-in tariff agreement with wpd, as well as forced the White Pines Wind Farm to close. It is estimated that wpd is seeking to recoup $\$ 100$ million from the government of Ontario, but this may not be the only impact (Global News, 2018). In an interview with The Globe and Mail, Berlin's ambassador to Canada warned, "Obviously, every incoming government has the right to change policy direction. But to have a unilateral cancellation pushed through by law that way is unsettling for the company, but is also something that will unsettle other potential investors" (The Globe and Mail, 2018). This example makes it clear that a lack of policy commitment can have 
detrimental effects to firms, environmental outcomes, and governments. The literature reaffirms this assertion. In a comprehensive review of carbon policy uncertainty, Romano and Fumagalli (2018) conclude that carbon tax uncertainty often results in delayed investment in greener technologies, slowing the achievement of environmental targets. Thus, when studying the impact of environmental policies, policy commitment is an important aspect to consider. Motivated by events observed in practice and the scientific literature, we consider the following research questions:

- What is the impact of policy commitment on the maximum achievable social welfare and optimal tax on carbon?

- How does firm profit and environmental impact change between the commitment and no commitment policies?

In this dissertation, we further explore the impact of policy commitment on the success of a carbon tax policies by directly comparing the optimal tax, social welfare, and firm profit under commitment and no commitment scenarios. Our relation to existing literature is found in Section 2. More specifically, we determine the optimal carbon tax a regulator sets for a monopolistic, profit-maximizing, pollution-producing firm in order to maximize social welfare, which depends on the firm's profit and associated environmental impact and consumer surplus. We consider a two-period game for the regulator-firm interaction. The regulator sets a tax level at the beginning of each period, and the firm responds to the tax by setting a price for their product and selecting a production process to maximize their profit. The firm can select a green or dirty production process, where the green production process yields less emissions per product but at a higher per-unit production cost. We also consider that consumers are willing to pay more when a greener production process is used.

Our key contributions come from comparing the optimal decisions made by the regulator and firm in a commitment and a no commitment scenario. In the commitment scenario, the regulator commits to a fixed tax over both periods at the beginning of the first period, allowing the firm to plan for future decisions. In the no commitment model, the regulator sets a tax at the beginning of each period, but maintains the same tax level in the second period. In other words, at the beginning of the first period, the firm has no information about the tax that will be set in the second period (or if there will even be a tax at all), impeding long-term planning for the firm. This no commitment model reflects the scenario in which a regulator renews a tax policy without guaranteeing the policy's renewal to the firm when it is first introduced.

The key contributions of our work are the following: 
- a regulator can achieve a higher social welfare under the commitment policy, with a lower optimal tax level under certain conditions

- the firm profit and consumer surplus are higher, and the environmental impact is lower under the commitment policy when compared to the no commitment policy at any tax level

- the outcomes in the commitment policy are less sensitive to small deviations from the optimal tax than the outcomes in the no commitment policy

These findings can provide insights for policymakers designing carbon tax policies by shedding light on the impact commitment has on a policy's effectiveness.

The remainder of the dissertation is organized as follows. We discuss the related research on sustainable operations management and environmental economics in Section 2. The game-theoretic model is formulated in Section 3 and analyzed in Section 4. We provide numerical examples in Section 5. Section 6 discusses the theoretical and managerial insights obtained from out work and Section 7 concludes the dissertation. 


\section{Chapter 2}

\section{Related Work}

Our research is related to two streams of literature: sustainable operations management and environmental economics. Environmental polices are being used by governments around the world as a mechanism to regulate greenhouse gas emissions. Many of these policies aim to incentivize firms to switch to a greener production technology, for example, through subsidies to make green technologies cheaper, or through taxes that make polluting technologies more expensive (Yuyin and Jinxi, 2018). As a result, supply chain managers must consider the costs these environmental policies have on their operations and adjust their decisions accordingly (Drake and Spinler, 2013).

In the operations management literature, technology choice under a carbon tax policy is well studied. Closely related to our work, Krass et al. (2013) determine the tax level required to induce a firm to switch to a green technology in their production process under a fixed carbon tax policy. Krass et al. (2013) conclude that higher tax levels may initially induce the use of green technologies, but larger tax increases may cause a switch back to dirty technologies, highlighting the non-monotone behaviour of a carbon tax. Investigating a firm's technology and capacity decisions under a fixed carbon tax policy, Drake et al. (2016) study how profits and emissions differ under a cap-and-trade policy. Shen et al. (2020) examine the influence of a fixed carbon tax on green technology adoption in supply chains with competition and pollution-sensitive demand. The impact of carbon taxes and carbon tariffs on green technology choice and carbon leakage is studied by Drake (2018). Gao and Zheng (2017) consider a three-stage Stackelberg game between a firm able to invest in green technology and a regulator that sets a fixed tax. Interestingly, Gao and Zheng (2017) consider the firm to be the Stackelberg leader to model the scenario where the regulator has low commitment power. Studying the optimal carbon tax policy under competition between green and dirty firms, Jin et al. (2018) consider a fixed tax rate that 
may differ between the two firms. Similar to all the papers discussed in this research stream, we consider how a carbon tax policy impacts the production technology chosen by a firm, and thus the firm's emissions output. However, the cited works assume an unchanging tax rate, allowing firms to plan ahead. Some degree of policy uncertainty is a reality and will thus plays a role in the adoption of environmental policies by firms (Romano and Fumagalli, 2018). To consider the impact of policy uncertainty, we directly compare a commitment and no commitment carbon tax policy over multiple periods. This comparison sheds light on the impact policy commitment has on the success of a tax policy - providing insights that are missed when policy uncertainty is not considered.

Carbon tax policies are also well studied in the environmental economics literature. $\mathrm{Yu}$ et al. (2019) examine the influence of a fixed and progressive carbon tax on green technology adoption in supply chains with competition and pollution-sensitive demand. Sinha et al. (2013) consider a mining company faced with extraction technology choices that vary in their environmental impact, with the regulator selecting a new tax level in every period to maximize social welfare. Unlike our work, Sinha et al. (2013) do not compare commitment and no commitment policies. However, some articles in this stream do consider uncertainty when studying carbon tax policies. One way policy uncertainty is addressed in the literature is when the continuation or commencement of the carbon tax is uncertain. Using a real options approach, Reedman et al. (2006) study the uptake of electricity-generation technologies varying in greenness levels, under a carbon tax rate that comes into effect at a certain date, then comparing these results with that of a policy that commences at an uncertain date. Fan et al. (2010) study firms facing uncertainty regarding whether there will be a carbon tax in the next period, with a given probability. Uncertainty regarding the tax level set by the regulator is also studied. Di Lorenzo et al. (2012) study the emissions decisions of a power-plant faced with an uncertain carbon tax rate which follows a normal probability distribution. Similar to these works, we study the decisions made by firms under a carbon tax policy and (excluding Yu et al. (2019)), we also explore the impacts of carbon tax policy uncertainty on firm profit and pollution output. Unlike these works, we consider the case where the firm has no information about the tax that will be set in each phase. We do not assume the firm has any information about the probability of a specific tax level being realized or the tax policy commencing. This assumption relies on some level of commitment by the regulator, that is, where the regulator 'commits' to making decisions based on a probability distribution that is known to the firm. We instead study the scenario with no commitment by the regulator, resulting in myopic behaviour from the firm even though the firm is forward looking. We aim to provide a baseline for no commitment. We then compare the results of the no commitment and commitment scenario - where the regulator commits to a single tax level for multiple 
periods at the beginning of the planning horizon. We also consider this problem from the perspective of rational, social-welfare maximizing regulator, not just the firm, a perspective that is missing from these works (except for Sinha et al. 2013).

To the best of our knowledge, our work is the first to provide a direct comparison between a multi-period commitment and no commitment carbon tax policy. Moreover, we consider a monopolistic firm faced with a discrete production technology choice that varies in pollution and price per unit, and pollution-sensitive demand. We analyze the decisions made by the regulator and the firm, leading to the differences in optimal tax level, firm profit, environmental impact, and social welfare. This leads to insights into the effect of regulator commitment on carbon tax policy success. 


\section{Chapter 3}

\section{Model Formulation}

This section presents a two-period, game-theory model for the interaction between a monopolistic firm acting in response to the tax set by a social welfare maximizing regulator. The regulator, being the Stakelberg leader, first sets the tax, followed by the firm selecting their optimal production technology and price. In the remainder of this section we present and discuss the decision models of the firm (Section 3.1) and the regulator (Section 3.2), and end with a detailed description of the game dynamics (Section 3.3). Table 3 outlines the main notations used throughout this dissertation.

\subsection{Firm's Decision Model}

In the $i^{\text {th }}$ period, $i \in\{1,2\}$, the firm sells their product to consumers at a price, $p_{i}$, and selects a production technology, $s_{i}^{j}$, where $j$ indicates the technology type. For simplicity, we consider a firm faced with two technology choices, that is, $j \in\{g, d\}$ which represent the green and dirty technology choices, respectively. The technology choice specifies the pollution emitted per produced unit when using the selected technology. The green technology choice emits less pollution per product than the dirty technology choice. Consequently, $1 \leq s_{i}^{g}<s_{i}^{d}{ }^{1}$. The pollution emitted per produced unit when using a particular technology does not change over each period, that is $s_{1}^{d}=s_{2}^{d}$ and $s_{1}^{g}=s_{2}^{g}$. In particular, the demand for the product in the first period is:

\footnotetext{
${ }^{1}$ Both $s_{i}^{g}$ and $s_{i}^{d}$ must be greater than or equal to 1 due to the structure of the cost function in (3.3), to ensure that the variable cost decreases as the firm chooses a dirtier technology.
} 


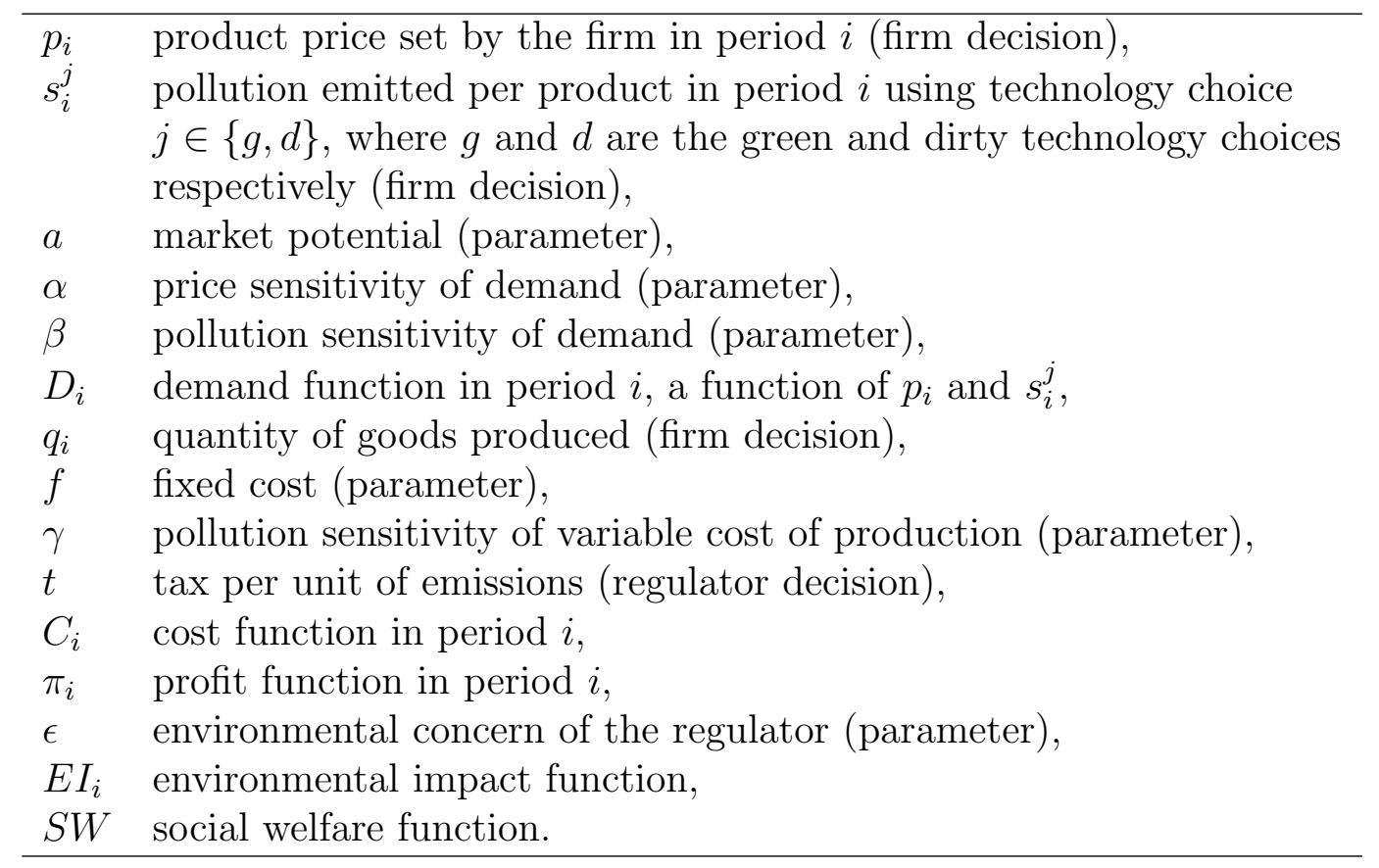

Table 3.1: Main Notations

$$
D_{1}\left(p_{1}, s_{1}^{j}\right)=a-\alpha p_{1}-\beta s_{1}^{j}
$$

Where $a>0$ is the market potential, and $\alpha>0$ and $\beta>0$ are the price and pollution sensitivity parameters, respectively. We assume demand decreases with price in accordance with the Law of Demand. In addition, the demand for the product decreases when the firm chooses a more polluting process, as it is assumed consumers are willing to pay more for a greener product (following Gao and Zheng (2017); Jin et al. (2018); Shen et al. (2020)).

The demand in the second period follows a similar structure, but we suppose consumers in the second period are sensitive to the technology choice of the firm in both the first and second period, linking the demand across both periods. This models consumers that are sensitive to a firm's pollution history or the corporate environmental reputation of a firm. It is known that corporate reputation regarding environmental issues influences consumer demand in the long term (Mohr and Webb, 2005). Environmentally irresponsible events, such as the BP oil spill in 2010, can damage corporate environmental reputation, with negative impacts lasting long after the event takes place (Lin et al., 2016). Applying the consideration of corporate environmental responsibility to our model, we consider that consumers are influenced by the firm's environmental reputation established in the first 
period through the firm's initial technology choice. Thus, the demand faced by the firm in the second period is:

$$
D_{2}\left(p_{2}, s_{1}^{j}, s_{2}^{j}\right)=a-\alpha p_{2}-\beta\left(s_{1}^{j}+s_{2}^{j}\right)
$$

For simplicity, we assume that both the first and second period technology choices are weighted equally (by $\beta$ ) in the demand function for the second period. However, our numerical exploration suggests our results hold even when $s_{1}^{j}$ and $s_{2}^{j}$ have different weightings, see Section 5.1.

The cost of producing a product depends first on the fixed cost, $f$. The cost relating to the technology choice is captured by the variable cost of production term, $\frac{\gamma q_{i}}{s_{i}^{j}}$, where $\gamma>0$ is the variable cost of production parameter, and $q_{i}$ is the quantity of products produced in period $i$. We assume that a technology that results in less pollution per product has a higher variable cost of production, similar to Bi et al. (2017); Yenipazarli and Vakharia (2015); Yu et al. (2016). If this trade-off does not exist, then the technology choice of the firm will be trivial - that is, the firm will be able to choose a technology that is both inexpensive and green, as a greener technology reduces tax and increases demand. The variable cost of production parameter, $\gamma$, captures the difference in variable costs between green and dirty technologies. As $\gamma$ increases, the firm saves more when switching to dirtier technologies. The final cost faced by the firm is the tax paid to the regulator based on the firm's pollution output. To encourage the firm to make greener technology choices, the regulator sets a tax rate, $t$, per unit of pollution emitted (Krass et al., 2013). The firm emits $s_{i}^{j} q_{i}$ units of pollution, and thus pays $t s_{i}^{j} q_{i}$ in taxes. Consequently, the total cost faced by the firm in period $i$ is the sum of the fixed cost, variable cost, and tax paid to the regulator, outlined in Equation (3.3).

$$
C_{i}\left(s_{i}^{j}, q_{i}\right)=f+\frac{\gamma q_{i}}{s_{i}^{j}}+t s_{i}^{j} q_{i}
$$

The firm is profit-maximizing, that is, they are only concerned with how much they pollute in regards to how it impacts their profit. The profit is defined as the revenue (the demand times the price) minus the cost. At equilibrium, $q_{i}=D_{i}\left(p_{i}, \boldsymbol{s}_{\boldsymbol{i}}^{\boldsymbol{j}}\right)$, and thus the profit of the firm in period 1 is:

$$
\pi_{1}\left(p_{1}, s_{1}^{j}\right)=p_{1} D_{1}\left(p_{1}, s_{1}^{j}\right)-C_{1}\left(s_{1}^{j}, D_{1}\left(p_{1}, s_{1}^{j}\right)\right)
$$

and the profit in period 2 is: 


$$
\pi_{2}\left(p_{2}, s_{1}^{j}, s_{2}^{j}\right)=p_{2} D_{2}\left(p_{2}, s_{1}^{j}, s_{2}^{j}\right)-C_{2}\left(s_{2}^{j}, D_{2}\left(p_{2}, s_{1}^{j}, s_{2}^{j}\right)\right)
$$

Substituting the appropriate demand and cost functions, (3.1), (3.2), and (3.3), into the profit functions (3.4) and (3.5), the profit in period 1 can be written as:

$$
\pi_{1}\left(p_{1}, s_{1}^{j}\right)=p_{1}\left(a-\beta s_{1}^{j}-\alpha p_{1}\right)-\frac{\gamma\left(a-\beta s_{1}^{j}-\alpha p_{1}\right)}{s_{1}^{j}}-s_{1}^{j} t\left(a-\beta s_{1}^{j}-\alpha p_{1}\right)-f
$$

and the profit in period 2 as:

$$
\begin{array}{r}
\pi_{2}\left(p_{2}, s_{1}^{j}, s_{2}^{j}\right)=p_{2}\left(a-\alpha p_{2}-\beta\left(s_{1}^{j}+s_{2}^{j}\right)\right)-\frac{\gamma\left(a-\alpha p_{2}-\beta\left(s_{1}^{j}+s_{2}^{j}\right)\right)}{s_{2}^{j}}- \\
s_{2}^{j} t\left(a-\alpha p_{2}-\beta\left(s_{1}^{j}+s_{2}^{j}\right)\right)-f .
\end{array}
$$

The total profit, $\pi_{\text {Total }}$, is obtained by summing the first and second period profits, equations (3.6) and (3.7).

\subsection{Regulator's Decision Model}

The regulator sets a tax, $t$, in order to maximize social welfare. The social welfare depends on the firm's total profit, previously defined in Section 3.1, the environmental impact of the firm's activities, and consumer surplus.

The environmental impact in period $i, E I_{i}$, is proportional to the total pollution emitted by the firm, and is defined as:

$$
E I_{i}=\epsilon D_{i} s_{i}^{j}
$$

Where $\epsilon$ is the environmental concern parameter of the regulator and $D_{i} s_{i}^{j}$ is the firm's total emissions output from producing $D_{i}$ products with technology $s_{i}^{j}$. We suppose society is concerned with the general advancement of climate change, or about mitigating environmental damages in their region. As the regulator and society's environmental concern 
grows, so does $\epsilon$. In this dissertation, the only damage to the environment comes from the firm's production emissions.

We also consider consumer surplus, the benefit consumers obtain when purchasing goods at a lower price than they are willing to pay (Marshall, 2009). Mathematically, consumer surplus is the area under the demand curve above the price set by the firm, i.e. the optimal price (Krass et al., 2013). That is,

$$
C S_{i}=\int_{p_{i}^{*}}^{p_{\max }} D_{i}\left(p_{i}\right) d p_{i}
$$

The maximum price, $p_{\max }$, is the price at which the demand is zero.

Thus, the social welfare function considered by regulator is:

$$
S W=\sum_{i=1}^{2}\left(\pi_{i}+C S_{i}-E I_{i}\right)
$$

The social welfare function, which reflects the concerns of the regulator and society as a whole, captures the trade-off between firm profits, consumer surplus, and environmental damages.

We suppose the regulator does not include tax revenue in the social welfare function, following Barnett (1980); Requate (2006) and others. Including a tax revenue term in the social welfare function would cancel out the tax the firm pays to the regulator. In this case, the tax the firm pays to the regulator, as well as the tax revenue the regulator receives, would not be considered in the regulator's decision. To prevent this, along with any adversarial relationship between the regulator and the firm, we omit the tax revenue term. In our model, the regulator does not view the tax as a means of revenue generation, but as a means to regulate firm emissions.

\subsection{Game Dynamics}

The game dynamics depend on whether or not the regulator commits to a tax policy. When the regulator does not pre-commit to a fixed tax over both periods, the game dynamics follow Figure 3.1(a). The regulator chooses a single tax to maximize social welfare over both periods, but does not disclose this information to the firm at the beginning of the first

period. From the point of view of the firm, the regulator sets a tax at the beginning of the 
first period, and is then free to set a new tax at the beginning of the second period. This lack of commitment induces the firm to behave myopically, even though we consider that the firm is forward-looking. The firm is indeed aware that their first period technology choice will impact the second period demand. However, the firm is unaware of the tax that will be set in the second period, nor its distribution, making them unaware of how the first period technology choice will impact the cost faced in the second period. Consequently, the firm cannot quantify the cost or benefit of the first period technology choice on the second period profit, even though the firm is forward-looking. Thus, the firm will maximize their current profit in each of the two periods independently, i.e., exhibit myopic behavior.

The resulting myopic firm behaviour in the case of no commitment arises because the firm cannot compute an expected second period tax, since there is no information as to what the second period tax will be (no distribution nor estimated moments are available). Our work challenges the assumption that firms are aware of the tax that will be set by the regulator in future periods. Some works have challenged this assumption by considering that firms do not know for certain what the future tax will be, but they know the probability distribution of the future tax (see Section 2). We remove the assumption that the firm can compute an expected tax in the second period based on a probability distribution. In practice, there are known cases where players are unable to construct reliable probability distributions to account for uncertainty. For example, the government of Alberta anticipated a selling price of $\$ 58$ per barrel of oil in their 2020 budget (Government of Alberta, 2020). However, this forecast was around 25\% too high as of March 2020, attributed largely to the coronavirus pandemic, resulting in the Treasury Board overestimating provincial revenue by hundreds of millions of dollars (CTV News, 2020). In regards to this overestimation, the Premier of Alberta claimed, "There is no point in us making significant changes to fiscal policy right now when nobody knows how long and how deep the impact of the coronavirus downturn will be" (CTV News, 2020). This example highlights that in practice, there are cases where forecasts of future events can be extremely unreliable. Moreover, uncertainties such as the coronavirus pandemic may make forecasting future events extremely difficult. In light of this example, we consider the case where the firm does not have enough information to estimate the probability distribution of the tax in the second period. However, we acknowledge that assuming the firm has no information about the tax set by the regulator in the second period comes with its own modelling and practical shortcomings. Although abandoning the common prior assumption may be extreme, this work provides a lower bound on outcomes in the case of no policy commitment - exploring the outcomes when the firm is completely unable to anticipate the future tax.

On the other hand, when the regulator pre-commits to a single tax, and informs the firm that they are pre-committing for both periods, the game dynamics follow Figure 3.1(b). 
Due to the regulator commitment, the firm can plan their decisions for both periods at the beginning of the planning horizon.

(a) No regulator commitment, myopic firm (red)

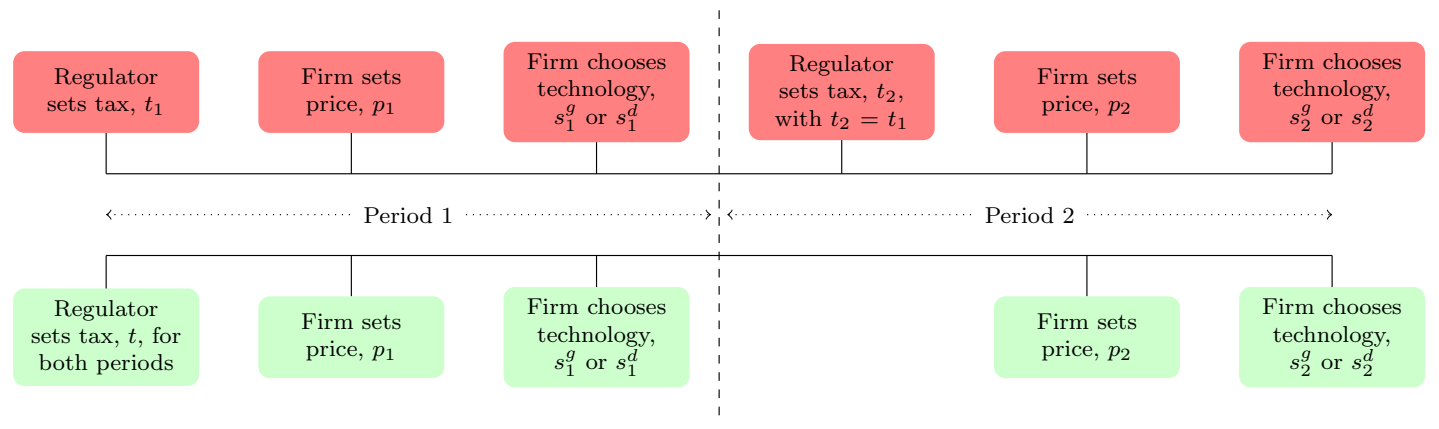

(b) Regulator commitment, forward-looking firm (green)

Figure 3.1: Game dynamics. Top (red) outlines game dynamics in the no commitment case, bottom (green) outlines game dynamics in the commitment case. 


\section{Chapter 4}

\section{Model Analysis}

In this section we present analytical results for the two cases: no regulator commitment and regulator commitment, and end the section with a direct comparison of the results of each case. Throughout the analysis, we assume the following:

- The firm is rational and the regulator sets the tax to ensure the firm participates in the market.

- The firm chooses the green technology if they are indifferent between choosing the green and dirty technology (i.e., when either choice yields the same profit)

- For tractability purposes, the firm does not discount future profits, and the regulator does not discount future profits, consumer surplus or environmental impact

\subsection{The case of no regulator commitment}

Here we analyze the decisions of the firm and regulator in the no commitment scenario, with game dynamics following Figure 3.1(a). Due to the lack of regulator commitment, the firm behaves myopically (even though the firm is forward-looking), maximizing their profit in each period sequentially. The regulator chooses a single tax to maximize social welfare over both periods (assuming the firm behaves myopically), but does not disclose this information to the firm at the beginning of the first period. Instead, the regulator only commits to their chosen tax level at the beginning of each period, not over both periods from the beginning. From the point of view of the firm, the regulator sets a tax at 
the beginning of the first period, and then sets another, potentially the same, tax at the beginning of the second period.

\subsubsection{First Period}

The regulator will set a tax, $t$, at the beginning of the first period. The firm's first period profit is defined by (4.1):

$$
\pi_{1}\left(p_{1}, s_{1}^{j}\right)=-\frac{\gamma\left(a-\beta s_{1}^{j}-\alpha p_{1}\right)}{s_{1}^{j}}+p_{1}\left(a-\beta s_{1}^{j}-\alpha p_{1}\right)-s_{1}^{j} t\left(a-\beta s_{1}^{j}-\alpha p_{1}\right)-f .
$$

The firm will choose $p_{1}^{*}$ and $s_{1}^{j *} \in\left\{s_{1}^{g}, s_{1}^{d}\right\}$ to maximize (4.1). Setting the derivative of (4.1) with respect to $p_{1}$ to zero and solving for $p_{1}$ gives the optimal price, $p_{1}^{*}$. The second

order condition, namely, $\frac{d \pi_{1}}{d p_{1}}<0$, is always satisfied, since $\frac{d \pi_{1}}{d p_{1}}=-2 \alpha<0$ since we assume $\alpha>0$, which ensures $p_{1}^{*}$ yields the maximum profit. The optimal price for the first period is:

$$
p_{1}^{*}=\frac{a s_{1}^{j *}+\left(s_{1}^{j *}\right)^{2} t \alpha-\left(s_{1}^{j *}\right)^{2} \beta+\alpha \gamma}{2 s_{1}^{j *} \alpha} .
$$

Thus, the optimal profit is given by:

$$
\pi_{1}\left(p_{1}^{*}, s_{1}^{j *}\right)=\frac{\left.\alpha^{2} \gamma^{2}+\left(s_{1}^{j *}\right)^{2}\left(a-s_{1}^{j *}(\beta+\alpha t)\right)^{2}-4 \alpha f\right)+2 \alpha \gamma s_{1}^{j *}\left(s_{1}^{j *}(\beta+\alpha t)-a\right)}{4 \alpha\left(s_{1}^{j *}\right)^{2}}
$$

where $\pi_{1}\left(p_{1}^{*}, s_{1}^{j *}\right)=\max \left\{\pi_{1}\left(p_{1}^{*}, s_{1}^{g}\right), \pi_{1}\left(p_{1}^{*}, s_{1}^{d}\right)\right\}$.

That is, the firm will compare its profit at each technology choice, and select the technology that yields a higher profit at each tax level. The optimal technology choice depends on the tax set by the regulator. That is, there may not be one technology choice that maximizes the firms profit at every tax level.

Proposition 1. Suppose the the market size, $a$, is sufficiently large to guarantee a positive demand, and the pollution sensitivity of demand, $\beta$, is sufficiently small (otherwise the firm always chooses the green technology). Then there exists a tax, $t_{\text {critical }}=\frac{\gamma}{s_{1}^{d} s_{1}^{g}}-\frac{\beta}{\alpha}$, such 
that the firm is indifferent between adopting either technology. The firm will choose the dirty technology if $t<t_{\text {critical }}$ and the green technology if $t \geq t_{\text {critical }}$.

Proof. Following the optimal profit given by Equation (4.3), we obtain the solution of the equation $\pi_{1}\left(p_{1}^{*}, s_{1}^{g}\right)=\pi_{1}\left(p_{1}^{*}, s_{1}^{d}\right)$. We determine that $t_{\text {critical }}=\frac{\gamma}{s_{1}^{d} s_{1}^{g}}-\frac{\beta}{\alpha}$ makes this statement true, so long as $a \geq \frac{\alpha \gamma s_{1}^{d}+\alpha \gamma s_{1}^{g}}{s_{1}^{d} s_{1}^{g}}$, and $\beta \leq \frac{\alpha \gamma}{s_{1}^{d} s_{1}^{g}}$. We then solve the inequality $\pi_{1}\left(p_{1}^{*}, s_{1}^{g}\right)<\pi_{1}\left(p_{1}^{*}, s_{1}^{d}\right)$ to determine the tax levels at which the dirty technology is preferred. This occurs when $0 \leq t<t_{\text {critical }}$, provided the conditions from above are met. Similarly, $\pi_{1}\left(p_{1}^{*}, s_{1}^{g}\right) \geq \pi_{1}\left(p_{1}^{*}, s_{1}^{d}\right)$ when $t \geq t_{\text {critical }}$.

Note that in the assumptions of Proposition 1 we focus only on cases where the green or dirty technology is not superior at every tax level, otherwise the technology decision of the firm is trivial. That is, we assume that by appropriately setting the tax, the regulator can induce either technology choice in the first period. In other words, we assume that the critical tax exists, and $t_{\text {critical }}>0$.

Proposition 2. The following are characteristics of the critical tax level:

1. The critical tax increases with pollution sensitivity of variable cost, $\frac{\partial t_{\text {critical }}}{\partial \gamma}>0$

2. The critical tax increases with price sensitivity of demand, $\frac{\partial t_{\text {critical }}}{\partial \alpha}>0$

3. The critical tax decreases with pollution sensitivity of demand, $\frac{\partial t_{\text {critical }}}{\partial \beta}<0$

Proof. Differentiating $t_{\text {critical }}$ with respect to $\gamma, \alpha$ and $\beta$ proves the result.

Proposition 2 provides intuitive characteristics of the critical tax level. First, as the variable cost of production increases, it means the difference in cost between dirty and green technologies is increasing. Thus, a higher tax is needed in order for the firm to switch to a green technology to compensate for the higher variable cost. Second, as consumers are more sensitive to price, a higher tax is needed to induce a green technology choice since pollution output impacts demand less. Third, as consumers become more sensitive to pollution, a lower tax is needed to induce the firm to choose the green technology. 


\subsubsection{Second Period}

Following the method of analysis of the first period, the optimal price and maximum profit in the second period is:

$$
\begin{aligned}
p_{2}^{*} & =\frac{\alpha \gamma+a s_{2}^{j *}-\beta s_{1}^{j *} s_{2}^{j *}-\beta\left(s_{2}^{j *}\right)^{2}+\alpha\left(s_{2}^{j *}\right)^{2} t}{2 \alpha s_{2}^{j *}}, \\
\pi_{2}\left(p_{2}^{*}, s_{1}^{j *}, s_{2}^{j *}\right) & =\frac{1}{4 \alpha\left(s_{2}^{j *}\right)^{2}}\left(a^{2}\left(s_{2}^{j *}\right)^{2}-2 a s_{2}^{j *}\left(\alpha \gamma+s_{2}^{j *}\left(\beta\left(s_{1}^{j *}+s_{2}^{j *}\right)\right.\right.\right. \\
& \left.\left.\left.+\alpha s_{2}^{j *} t\right)\right)-4 \alpha f\left(s_{2}^{j *}\right)^{2}+\left(\alpha \gamma+s_{2}^{j *}\left(\beta\left(s_{1}^{j *}+s_{2}^{j *}\right)+\alpha s_{2}^{j *} t\right)\right)^{2}\right) .
\end{aligned}
$$

Recall from (3.2) that the demand faced by the firm in the second period depends on both the first and second period technology choices. Note that both the optimal price and the maximum profit in the second period depend on the technology choice of the first period, linking the decision of the first period to the second period.

Proposition 3. Suppose the the market size, $a$, is sufficiently large to guarantee a positive demand, and the pollution sensitivity of demand, $\beta$, is sufficiently small (otherwise the

firm always chooses the green technology). Then there exists a tax, $t_{\text {critical }}=\frac{\gamma}{s_{2}^{d} s_{2}^{g}}-\frac{\beta}{\alpha}$ from Proposition 1, such that

1. if the firm has chosen the green technology in the first period, then choosing the green or dirty technology in the second period yield identical second period profits, that is, $\pi_{2}\left(p_{2}^{*}, s_{1}^{g}, s_{2}^{g}\right)=\pi_{2}\left(p_{2}^{*}, s_{1}^{g}, s_{2}^{d}\right)$

2. if the firm has chosen the dirty technology in the first period, then choosing the green or dirty technology in the second period yield identical second period profits, that is, $\pi_{2}\left(p_{2}^{*}, s_{1}^{d}, s_{2}^{d}\right)=\pi_{2}\left(p_{2}^{*}, s_{1}^{d}, s_{2}^{g}\right)$

Moreover, in either case, the firm will choose the dirty technology in the second period when $t<t_{\text {critical }}$ and the green technology when $t \geq t_{\text {critical }}$

Proof. We follow the same method used in the proof of Proposition 1 to obtain the result. 
It is important to note that we observe the symmetry in critical tax levels of the first and second period due to the fact that the parameters defining the model do not change throughout the game. In other words, we assume that the market conditions (such as market size, pollution sensitivity of demand, etc.) remain fixed.

The firm's optimal decision over both periods can be expressed as the 4 -tuple $\left(p_{1}^{*}, s_{1}^{j *}, p_{2}^{*}, s_{1}^{j *}\right)$. Since the form of $p_{1}^{*}$ and $p_{2}^{*}$ given a particular tax and technology choice are known, we are now interested in determining the optimal technology choices of the firm. We simplify the 4 -tuple notation to the technology choices of the firm, which we write as $\left(s_{1}^{j *}, s_{2}^{j *}\right)$.

Lemma 4.1.1. Combining the results of Proposition 1 and Proposition 3, we know that:

1. $\pi_{\text {Total }}\left(s_{1}^{j *}, s_{2}^{j *}\right)=\pi_{\text {Total }}\left(s_{1}^{d}, s_{2}^{d}\right)$ for $0 \leq t<t_{\text {critical }}$ and,

2. $\pi_{\text {Total }}\left(s_{1}^{j *}, s_{2}^{j *}\right)=\pi_{\text {Total }}\left(s_{1}^{g}, s_{2}^{g}\right)$ for $t \geq t_{\text {critical }}$.

Proof. This result immediately follows from Proposition 1 and Proposition 3, recalling the assumption that the firm chooses the green technology if they are indifferent between the green and dirty technology choice.

Lemma 4.1.1 states that at any tax below the critical tax level, the firm will choose the dirty technology in the first and second period. It also states that at any tax above the critical tax level, the firm will choose the green technology in both periods. Notice that no matter the tax set by the regulator, the firm will never switch its technology choice throughout the game. The technology decisions $\left(s_{1}^{g}, s_{2}^{d}\right)$ and $\left(s_{1}^{d}, s_{2}^{g}\right)$ are not inducible by the regulator under the no commitment policy. In other words, $\left(s_{1}^{g}, s_{2}^{d}\right)$ and $\left(s_{1}^{d}, s_{2}^{g}\right)$ will never be chosen by the firm. The firm never chooses the strategy $\left(s_{1}^{g}, s_{2}^{d}\right)$ due to the lack of regulator commitment, and the firm never chooses the strategy $\left(s_{1}^{d}, s_{2}^{g}\right)$ because it is a weakly dominated strategy.

The elimination of the strategy $\left(s_{1}^{g}, s_{2}^{d}\right)$ arises from a lack of regulator commitment. If the regulator chooses a tax below the critical tax level, we know that the firm will choose the dirty technology in the first period. In the second period, the firm will only be choosing between $\left(s_{1}^{d}, s_{2}^{d}\right)$ and $\left(s_{1}^{d}, s_{2}^{g}\right)$ since its first period decision to choose the dirty technology has already been made. Proposition 3 says that the firm will choose the dirty technology in the second period when the tax set by the regulator is lower than the critical tax. Similarly, if the regulator chooses a tax at or above the critical tax level, the firm will choose the green technology in the second period. Notice that the strategy $\left(s_{1}^{g}, s_{2}^{d}\right)$ was never considered. This strategy is not ruled out because it is dominated by another strategy, it is simply not possible for the firm to choose this strategy in this commitment structure. 
On the other hand, $\left(s_{1}^{d}, s_{2}^{g}\right)$ is a weakly dominated strategy. Below the critical tax level, we know that the strategy $\left(s_{1}^{d}, s_{2}^{d}\right)$ yields a higher profit than $\left(s_{1}^{d}, s_{2}^{g}\right)$. At or above the critical tax level, the firm will not choose the dirty technology in the first period, and thus will never choose the strategy $\left(s_{1}^{d}, s_{2}^{g}\right)$. However, assuming that the firm could make that choice, we know that the strategy $\left(s_{1}^{g}, s_{2}^{g}\right)$ yields a higher profit. Therefore, the strategy $\left(s_{1}^{d}, s_{2}^{g}\right)$ is weakly dominated and can be removed from consideration.

The fact that $\left(s_{1}^{d}, s_{2}^{g}\right)$ is a weakly dominated strategy makes sense given the structure of the model. Given the symmetry of the model between the two periods, apart from the demand functions, it would always be better for the firm to choose $\left(s_{1}^{g}, s_{2}^{d}\right)$ over $\left(s_{1}^{d}, s_{2}^{g}\right)$, no matter the tax level. That is, the strategy $\left(s_{1}^{d}, s_{2}^{g}\right)$ is dominated by $\left(s_{1}^{g}, s_{2}^{d}\right)$. This is because the demand in the second period is dependent on both the first and second period technology decision of the firm. The technology choice in the first period therefore has a greater impact on total profits than the technology choice of the second period. The first period technology choice impacts the demand in both the first and second period, while the second period technology choice only impacts the demand in the second period. We know from (3.1) and (3.2) that, all else being equal, the demand is lower when the firm chooses the dirty technology compared to when they choose the green technology, as it

is assumed consumers are sensitive to the emissions output of firms. Assuming that the firm will choose the dirty technology in one period and the green technology in the other, it is better for the firm to choose the dirty technology in the second period. This only negatively impacts the demand of the second period, while when the firm chooses the dirty technology in the first period, the demand is negatively impacted in the first and second period.

\subsection{The case of regulator commitment}

We now analyze the results in the commitment case, with game dynamics following Figure 3.1(b). At the beginning of the first period, the regulator commits to the tax level that will apply to both the first and second period. Thus, the firm can be forward-looking, using backwards induction to determine the optimal decision to maximize profit over both periods.

The firm's optimal decision over both periods consists of the optimal price and technology choice for the first and second periods. The optimal price set by the firm in the first and second periods can be calculated in the same way as Section 4.1 and the structure of the optimal prices are the same as in the case of no commitment. That is, the optimal price in the first and second period is given by (4.2) and (4.4) respectively. The prices 
set by the regulator in the commitment case follow the same form as the prices in the no commitment case because the two periods are linked only through the technology choices and not the prices. The price set in the first period has no impact on the price set in the second period, and vice versa. Recall that the only difference between the first and second period is that demand in the second period depends on both the first and second period technology choice. The price set by the firm in the first period has no impact on the second period and vice versa. Thus, regulator commitment has no impact on the form of the price set by the firm. However, this does not mean the prices set by the firm in the case of regulator commitment are the same as when the regulator does not commit. This is because the price set by the firm depends on the technology choice, which may differ in the commitment case.

Once the optimal prices are known, the firm compares the resulting profits from each of the technology choice combinations spanning both periods. More specifically, we compare the profit of when the technology choice of the firm is $\left(s_{1}^{g}, s_{2}^{g}\right),\left(s_{1}^{g}, s_{2}^{d}\right),\left(s_{1}^{d}, s_{2}^{g}\right)$, and $\left(s_{1}^{d}, s_{2}^{d}\right)$. These technology choices depend on the parameter values that define the model.

Due to the regulator commitment, the firm can look at the total profit functions from the beginning, and choose the technologies that maximize their total profit at every tax level. From Proposition 3, we know that before the critical tax level the firm will choose $\left(s_{1}^{d}, s_{2}^{d}\right)$ or $\left(s_{1}^{g}, s_{2}^{d}\right)$, and after the critical tax level the firm will choose $\left(s_{1}^{g}, s_{2}^{g}\right)$ or $\left(s_{1}^{d}, s_{2}^{g}\right)$.

Proposition 4. In the commitment case, $\left(s_{1}^{d}, s_{2}^{g}\right)$ is a weakly dominated strategy at every tax level.

Proof. By Proposition 3, this strategy is dominated by $\left(s_{1}^{d}, s_{2}^{d}\right)$ before the critical tax level, and weakly dominated by $\left(s_{1}^{g}, s_{2}^{g}\right)$ at or above the critical tax level.

Similar to the case of no commitment, $\left(s_{1}^{d}, s_{2}^{g}\right)$ is also a weakly dominated strategy when the regulator commits. However, recall from Section 4.1 that the strategy $\left(s_{1}^{g}, s_{2}^{d}\right)$ was not chosen by the firm due to the lack of regulator commitment. In the case of commitment, however, this strategy may yield the best outcome below the critical tax level. It may be advantageous for the firm to choose the green technology in the first period, even below the critical tax level, since the first period technology choice impacts both the first and second period demand. Since the firm maximizes their total profit in the case of regulator commitment, $\left(s_{1}^{g}, s_{2}^{d}\right)$ may be a viable strategy and is not ruled out.

Thus, in the case of regulator commitment, the firm chooses between the three strategies $\left(s_{1}^{g}, s_{2}^{g}\right),\left(s_{1}^{g}, s_{2}^{d}\right)$, and $\left(s_{1}^{d}, s_{2}^{d}\right)$. 
Lemma 4.2.1. In the case of regulator commitment, the firm will choose $\left(s_{1}^{g}, s_{2}^{g}\right)$ for $t \geq t_{\text {critical }}$.

Proof. Follows from Proposition 3 and 4.

In summary, in the case of regulator commitment, the firm will choose either $\left(s_{1}^{d}, s_{2}^{d}\right)$ or $\left(s_{1}^{g}, s_{2}^{d}\right)$ below the critical tax level, and $\left(s_{1}^{g}, s_{2}^{g}\right)$ at or above the critical tax level.

\subsection{Comparing the case of no commitment and com- mitment}

Here we analytically establish when and how the results of the commitment and no commitment cases differ.

We begin our comparative analysis with the total profit of the firm in both cases. At a particular tax level, the total profit of the firm in the commitment case will be greater than or equal to the total profit in the case of no regulator commitment (Lemma 4.3.1). We know that total the profit of the firm depends on the technology choice in both periods. Since, in the case of regulator commitment, the firm can plan its second period decisions from the beginning, the firm can maximize its total profit, rather than maximizing its profit period by period.

Lemma 4.3.1. The total profit of the firm in the case of commitment is greater than or equal to the total profit of the firm in the no commitment case at a particular tax level.

Proof. In the commitment case, the firm maximizes its total profit from the beginning in the first period. In the no commitment case, the firm maximizes its first period profit, then its second period profit given the decision it made in the firm period. In other words, the firm has an added maximization constraint in the no commitment scenario: its first period decisions. Adding a constraint to a mathematical program will never increase the feasibility region; using the same objective means the two-period case is never worse than the single-period case.

If the firm makes the same technology choice at every tax level in the commitment and no commitment case, the resulting profits will be the same. We know from Lemma 4.1 .1 and 
Lemma 4.2.1 that in both the commitment and no commitment cases, the firm will choose $\left(s_{1}^{g}, s_{2}^{g}\right)$ at or above the critical tax level. As such, the outcomes (firm profit, environmental impact, consumer surplus, and social welfare) will be the same above the critical tax level. We are interested in determining the differences between the two scenarios; to identify the difference, for the remainder of this section we only consider the case of the tax level below the critical tax level.

Proposition 5 states that we will only observe a different outcome between the commitment and no commitment case when the firm in the commitment case selects $\left(s_{1}^{g}, s_{2}^{d}\right)$, which only occurs below the critical tax level. Recall that the firm never chooses $\left(s_{1}^{g}, s_{2}^{d}\right)$ in the case of no commitment (Section 4.1.2), and always chooses $\left(s_{1}^{d}, s_{2}^{d}\right)$ below the critical tax level.

Proposition 5. The only way for the outcome to be different between the commitment and no commitment case at a particular tax level is if in the case of commitment, the firm chooses $\left(s_{1}^{g}, s_{2}^{d}\right)$. This only happens below the critical tax level.

Proof. Above the critical tax level, the firm will choose $\left(s_{1}^{g}, s_{2}^{g}\right)$ in both the case of commitment and no commitment (Lemma 4.1.1 and Lemma 4.2.1. In the case of no commitment, the firm will choose $\left(s_{1}^{d}, s_{2}^{d}\right)$ below the critical tax level. In the case of commitment, the firm will choose $\left(s_{1}^{d}, s_{2}^{d}\right)$ or $\left(s_{1}^{g}, s_{2}^{d}\right)$ below the critical tax level. Thus, the only way to get a different outcome between the commitment and no commitment case is when the firm chooses $\left(s_{1}^{g}, s_{2}^{d}\right)$.

We now wish to compare the social welfare between the two cases. Recall that the social welfare function defined by (3.10) is made up of the firm's total profit, consumer surplus, and environmental impact. We have already established that the total profit of the firm is greater than or equal to the total profit in the case of no regulator commitment. We obtain a similar result for the consumer surplus in Lemma 4.3.2.

Lemma 4.3.2. The total consumer surplus in the case of commitment is greater than or equal to the consumer surplus in the no commitment case at a particular tax level.

Proof. Recall from Proposition 5 that the outcomes of the commitment and no commitment scenarios only differ when the firm chooses $\left(s_{1}^{g}, s_{2}^{d}\right)$ in the commitment case and $\left(s_{1}^{d}, s_{2}^{d}\right)$ in the case of no commitment, which we know will only occur below the critical tax level. Thus we only need to prove that under the conditions which the firm chooses $\left(s_{1}^{g}, s_{2}^{d}\right)$, $C S_{\text {Total }}\left(s_{1}^{g}, s_{2}^{d}\right) \geq C S_{\text {Total }}\left(s_{1}^{d}, s_{2}^{d}\right)$, and we can restrict our search to below the critical tax 
level. The conditions under which the firm chooses $\left(s_{1}^{g}, s_{2}^{d}\right)$ over $\left(s_{1}^{d}, s_{2}^{d}\right)$, that is, when $\pi_{\text {Total }}\left(s_{1}^{g}, s_{2}^{d}\right) \geq \pi_{\text {Total }}\left(s_{1}^{d}, s_{2}^{d}\right)$, are outlined in the Appendix. Similarly, we also determine when $C S_{\text {Total }}\left(s_{1}^{g}, s_{2}^{d}\right) \geq C S_{\text {Total }}\left(s_{1}^{d}, s_{2}^{d}\right)$ below the critical tax level. The conditions where $\pi_{\text {Total }}\left(s_{1}^{g}, s_{2}^{d}\right) \geq \pi_{\text {Total }}\left(s_{1}^{d}, s_{2}^{d}\right)$ are the same as the conditions under which $C S_{\text {Total }}\left(s_{1}^{g}, s_{2}^{d}\right) \geq$ $C S_{\text {Total }}\left(s_{1}^{d}, s_{2}^{d}\right)$, proving the result.

Lastly, we must look at the environmental impact. Specifically, we must compare the environmental impact of the firm below the critical tax level when it selects $\left(s_{1}^{g}, s_{2}^{d}\right)$ in the commitment case and $\left(s_{1}^{d}, s_{2}^{d}\right)$ and in the case of no commitment.

Proposition 6. The total environmental impact resulting from the firm choosing $\left(s_{1}^{g}, s_{2}^{d}\right)$ is less than the environmental impact when the firm chooses $\left(s_{1}^{d}, s_{2}^{d}\right)$, for every $t \in\left[0, t_{\text {critical }}\right]$.

Proof. Recall from Section 3 that the emissions per unit produced given the technology choice of the firm does not change over each period, that is, $s_{1}^{d}=s_{2}^{d}$ and $s_{1}^{g}=s_{2}^{g}$. Thus for the sake of space we adopt the notation $s_{1}^{g}=s_{2}^{g}=s^{g}$ and $s_{1}^{d}=s_{2}^{d}=s^{d}$ when comparing the results of the environmental impact functions, but include the period notation in the function inputs to distinguish when the decisions are being made. We compare the relative values of the total environmental impacts $\left(E I_{\text {Total }}=E I_{1}+E I_{2}\right)$ when the firm chooses the dirty technology in both periods and when the firm chooses the green technology in the first period and the dirty technology in the second period. Applying the conditions of Proposition 1 that ensure the critical tax exists, we obtain the following results:

$$
\begin{aligned}
& \text { 1. }\left.E I_{\text {Total }}\left(s_{1}^{d}, s_{2}^{d}\right)\right|_{t=0}-\left.E I_{\text {Total }}\left(s_{1}^{g}, s_{2}^{d}\right)\right|_{t=0}=-\frac{1}{2} \epsilon\left(s^{d}-s^{g}\right)\left(\beta\left(s^{d}+s^{g}\right)-a\right)>0, \\
& \text { 2. }\left.E I_{\text {Total }}\left(s_{1}^{d}, s_{2}^{d}\right)\right|_{t=t_{\text {critical }}}-\left.E I_{\text {Total }}\left(s_{1}^{g}, s_{2}^{d}\right)\right|_{t=t_{\text {critical }}}=\frac{\epsilon\left(s^{d}-s^{g}\right)\left(a s^{d} s^{g}-\alpha \gamma\left(s^{d}+s^{g}\right)\right)}{2 s^{d} s^{g}}>0
\end{aligned}
$$

In addition, $E I_{\text {Total }}\left(s_{1}^{d}, s_{2}^{d}\right)$ and $E I_{\text {Total }}\left(s_{1}^{g}, s_{2}^{d}\right)$ are both linear in $t$. Thus, $E I_{\text {Total }}\left(s_{1}^{d}, s_{2}^{d}\right)>$ $E I_{\text {Total }}\left(s_{1}^{g}, s_{2}^{d}\right)$ for every $t \in\left[0, t_{\text {critical }}\right]$.

Combining the results of Lemma 4.3.1, Lemma 4.3.2 and Proposition 6, at any given tax level, the social welfare will be greater or equal in the commitment model compared to the no commitment model.

Proposition 7. At any tax level, $t$, the total social welfare over both periods will be greater or equal in the commitment model compared to the no commitment model. 
Proof. Recall that the social welfare, defined by $(3.10)$ is $\sum_{i=1}^{2}\left(\pi_{i}+C S_{i}-E I_{i}\right)$. At a particular tax level, we know that the firm profit and consumer surplus over both periods is greater or equal in the commitment case compared to the case of no commitment (Lemma 4.3.1, Lemma 4.3.2). By Proposition 5, we know that the outcomes can only be different between the two cases when the firm chooses $\left(s_{1}^{g}, s_{2}^{d}\right)$ in the case of regulator commitment, which occurs below the critical tax level when the firm will choose $\left(s_{1}^{d}, s_{2}^{d}\right)$ in the case of no commitment. More specifically, the environmental impacts in the commitment and no commitment cases will only differ below the critical tax level when the firm chooses $\left(s_{1}^{g}, s_{2}^{d}\right)$ in the case of regulator commitment and $\left(s_{1}^{d}, s_{2}^{d}\right)$ in the case of no commitment. From Proposition 6, we know that if the environmental impacts differ between the two cases at a particular tax level, it will be lower in the commitment case. Thus, at any tax level, the social welfare in the commitment case is greater than or equal to the social welfare in the case of no commitment.

In other words, if the regulator picked the same tax level for both the commitment and no commitment scenario, it is better for regulator to commit. However, the optimal tax, $t^{*}$, may be different in the commitment and no commitment model. This is because the regulator is rational and social welfare maximizing in both cases. Proposition 7 does not explicitly claim that the social welfare evaluated at the optimal tax in the commitment case is greater than the social welfare evaluated at the optimal tax in the case of no commitment. However, we now show that this is indeed the fact:

Proposition 8. The social welfare evaluated at the optimal tax in the commitment case is greater than the social welfare evaluated at the optimal tax in the case of no commitment. $S W_{c}\left(t_{c}^{*}\right) \geq S W_{n}\left(t_{n}^{*}\right)$.

Proof. We call the optimal tax of the commitment and no commitment case $t_{c}^{*}$ and $t_{n}^{*}$ respectively. We call the social welfare of the commitment and no commitment case $S W_{c}$ and $S W_{n}$ respectively. By Proposition 7 we know that $S W_{c}\left(t_{n}^{*}\right) \geq S W_{n}\left(t_{n}^{*}\right)$. However, by the definition of the optimal tax, $S W_{c}\left(t_{c}^{*}\right) \geq S W_{c}\left(t_{n}^{*}\right)$. By transitivity, $S W_{c}\left(t_{c}^{*}\right) \geq S W_{n}\left(t_{n}^{*}\right)$, proving the result.

Proposition 8 establishes that the optimal social welfare in the commitment case is higher than the optimal social welfare in the case of no commitment. In other words, when the regulator commits, they are always able to achieve an equal or greater social welfare when compared to a no commitment policy. 


\section{Chapter 5}

\section{Numerical Examples}

In this section we directly compare the results of the no commitment and commitment case, verifying many of the results of Section 4 and gaining insights into the optimal social welfare and tax levels. Lastly, we investigate the sensitivity of the critical tax level in the commitment and no commitment case. Due to the multiple periods in the model, the linked demand, and the discontinuous nature of the optimal social welfare function, determining the optimal tax, though feasible, is not possible to write in a concise manner. Instead, we derive the optimal social welfare function and tax level in Mathematica (Wolfram Research Inc., 2019), and numerically investigate their sensitivity and behavior in this section. Note that we use Mathematica's internal discretization methods to generate the plots in this section. $^{1}$

\subsection{Comparing the case of no commitment and com- mitment}

To compare the case of no regulator commitment and regulator commitment, we consider the following examples:

Example 1. Suppose $a=10, \alpha=2, \beta=1, \gamma=2, f=0, s_{i}^{g}=1, s_{i}^{d}=2$, with:

(a) $\epsilon=0.6$, low regulator concern for the environment

\footnotetext{
${ }^{1}$ Please see https://reference.wolfram.com/language/ref/Plot.html for details.
} 
(b) $\epsilon=0.8$, moderate regulator concern for the environment

(c) $\epsilon=1.1$, high regulator concern for the environment

Recall that the total optimal firm profit function for both the commitment and no commitment case, comprised of the sum of (4.3) and (4.5), is independent of the regulator's concern for the environment, $\epsilon$. That is, although the tax set by the regulator, which depends on $\epsilon$, impacts the profit of the firm, the optimal profit as a function of the tax does not depend on $\epsilon$ directly. Thus, we can analyze the decisions of the firm without differentiating between Example 1(a)-(c). The regulator's concern for the environment will become relevant when determining the optimal tax level. First we present the decisions of the firm in the case of no regulator commitment.

The firm will set their first period price as determined in (4.2). Evaluated at the parameters specified in Example 1 yields:

$$
p_{1}^{*}=\frac{2\left(s_{1}^{j^{*}}\right)^{2} t-\left(s_{1}^{j^{*}}\right)^{2}+10 s_{1}^{j^{*}}+4}{4 s_{1}^{j^{*}}}
$$

which depends on the technology choice of the firm as well as the tax set by the regulator. Figure 5.1 shows the optimal profit at a given tax level when the firm chooses the dirty technology (red) or when then firm chooses the green technology (green). The profit of the firm when using the green technology is equal to the profit of the firm when using the dirty technology only when the regulator sets the tax to the critical tax level, $\frac{1}{2}$ (cf. Proposition 1). Also by Proposition 1, the firm will choose the dirty technology from $0<t<\frac{1}{2}$, and the green technology from $t \geq \frac{1}{2}$, shown by the black dotted line which represents the optimal profit at any given tax level in Figure 5.1.

Recall that in the case of no regulator commitment, the firm behaves myopically. Thus in the second period, the firm maximizes its second period profit given its first period decision. The optimal price in the second period follows (4.4),

$$
p_{2}^{*}=\frac{2\left(s_{1}^{j *}\right)^{2} t-s_{1}^{j^{*}} s_{2}^{j^{*}}+10 s_{2}^{j^{*}}+4}{4 s_{2}^{j^{*}}}
$$

which depends on both the first and second period technology choice, and the tax set by the regulator. Figure 5.2 shows the profit in the second period evaluated at the optimal prices in the first and second period, given the possible technology choices in the first and 


\section{First Period Profit with No Regulator Commitment}

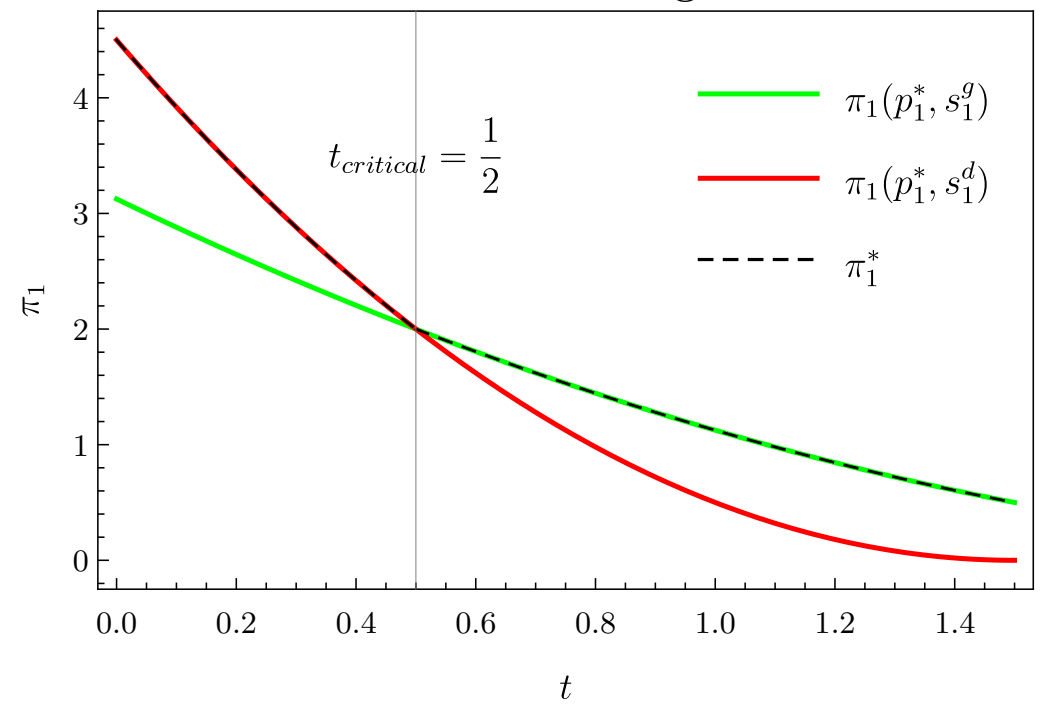

Figure 5.1: First period profit with no regulator commitment when the dirty (red) or green (green) technology is selected

second period. Since we know from the first period that the firm will choose the dirty technology in the first period below the critical tax and the green technology at or above the critical tax, it restricts the decision of the firm in the second period. More specifically, the firm can only choose between $\left(s_{1}^{d}, s_{2}^{g}\right)$ and $\left(s_{1}^{d}, s_{2}^{d}\right)$ below the critical tax, and $\left(s_{1}^{g}, s_{2}^{g}\right)$ and $\left(s_{1}^{g}, s_{2}^{d}\right)$ above the critical tax. At these parameter values, below the critical tax, the firm will choose the dirty technology in both periods, and the firm will choose the green technology in both periods at or after the critical tax level (Figure 5.2). The optimal profit function (black dotted line) in Figure 5.2 is discontinuous at the critical tax level.

In the case of regulator commitment, the firm can be forward looking since the tax level in the second period is known from the beginning of the first period. We can analyze the firm's decision with Figure 5.3, which shows the total profit given the firm's technology choices. That is, rather than looking at the profit period-by-period, the firm is able to maximize its total profit from the beginning when the regulator commits. By Figure 5.3, the firm will choose $\left(s_{1}^{d}, s_{2}^{d}\right)$ from $0 \leq t<0.1069,\left(s_{1}^{g}, s_{2}^{d}\right)$ from $0.1069 \leq t<\frac{1}{2}$, and $\left(s_{1}^{g}, s_{2}^{g}\right)$ when $t \geq \frac{1}{2}$.

We note that although the weightings of the first and second period technology choice in the second period demand are assumed equal (see equation (3.2)), our main results 


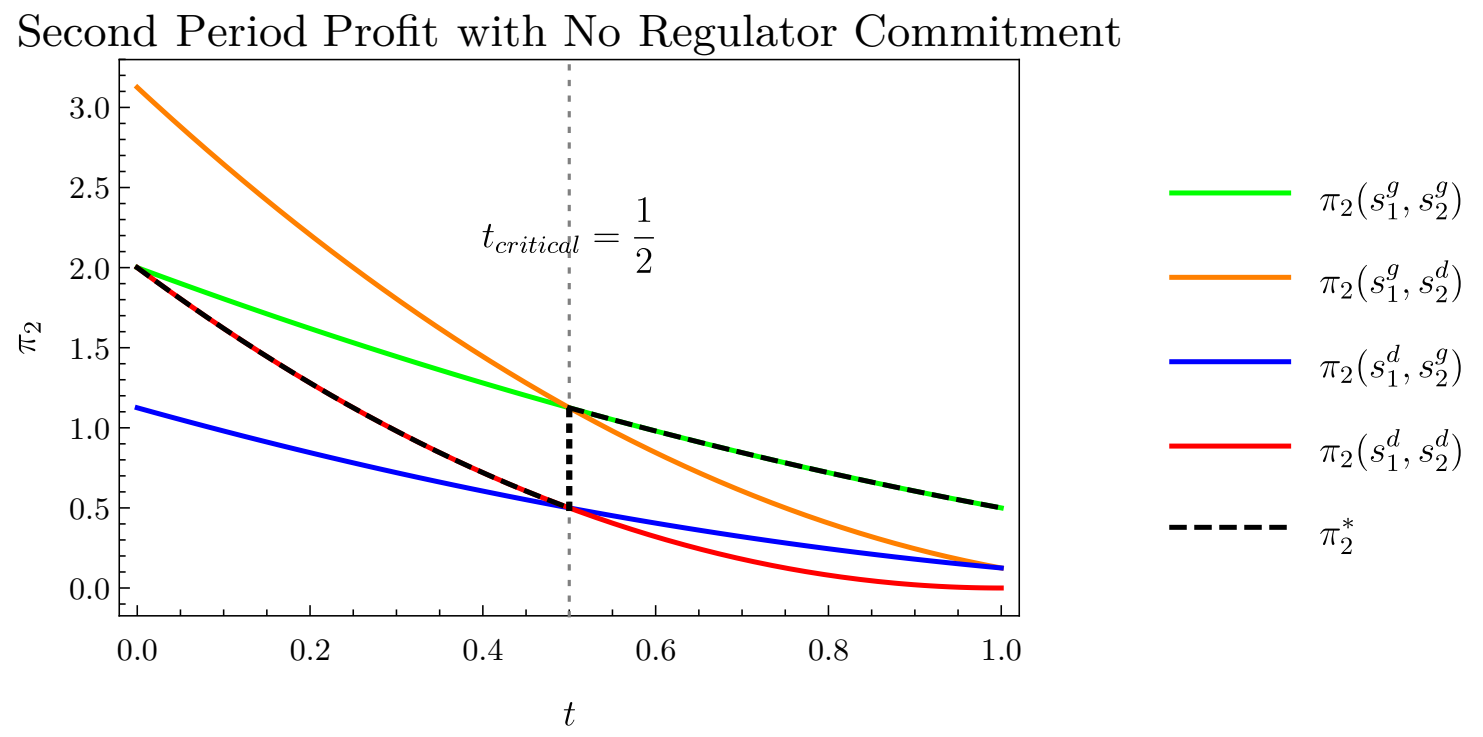

Figure 5.2: Second period profit with no regulator commitment given the firm's technology choice in both periods

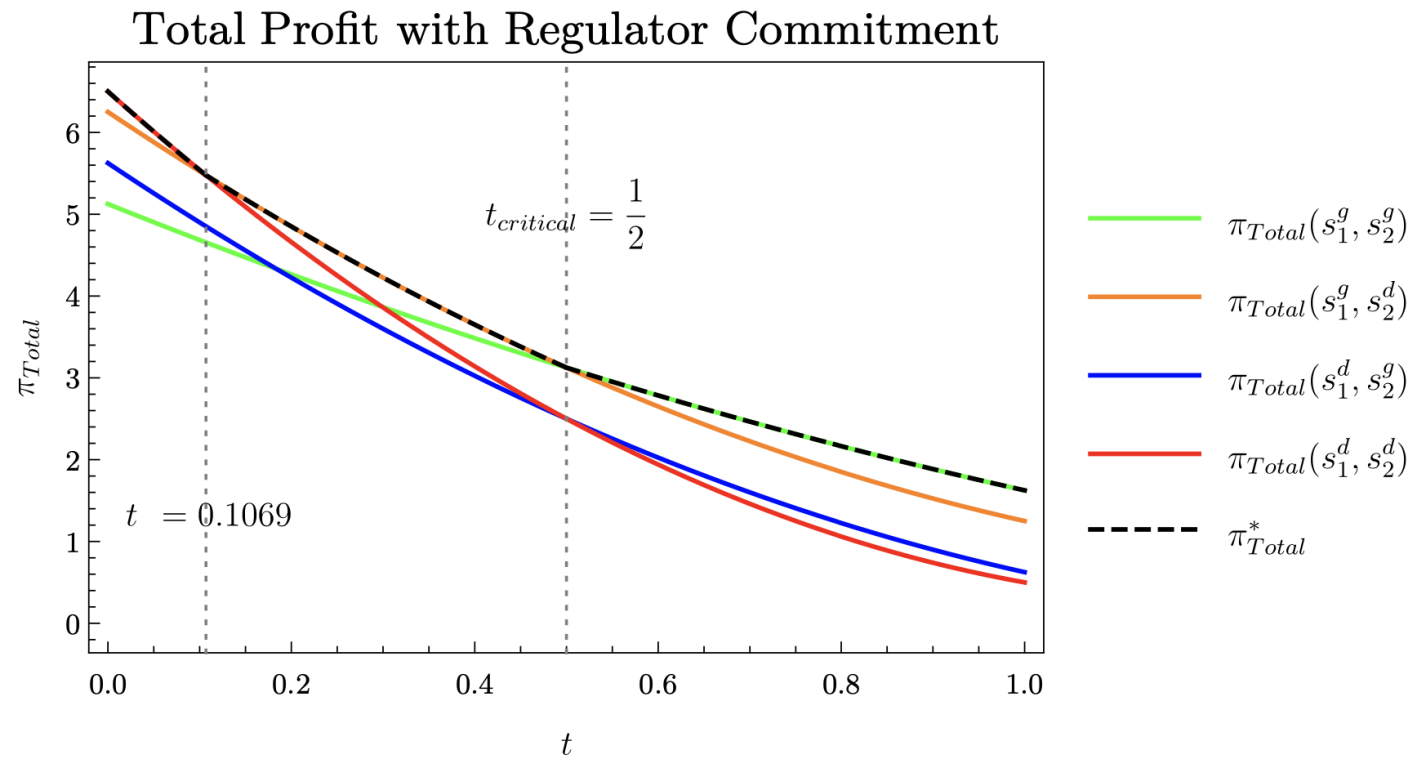

Figure 5.3: Total profit of the firm with regulator commitment given the firm's technology choice in both periods 
above hold even when the technology choices have different weightings. In particular, in the case of no commitment, the firm will still choose the dirty technology in both periods below the critical tax level and the green technology in both periods at or above the critical tax level. In the case of commitment, the firm will still choose the $\left(s_{1}^{g}, s_{2}^{g}\right)$ strategy at or above the critical tax level, and the $\left(s_{1}^{d}, s_{2}^{d}\right)$ or $\left(s_{1}^{g}, s_{2}^{d}\right)$ strategy below the critical tax level. However, the switching point between the $\left(s_{1}^{g}, s_{2}^{g}\right)$ and $\left(s_{1}^{g}, s_{2}^{g}\right)$ strategy, $t=0.1069$ in the case of Example 1 with equal weightings, is impacted if different weightings are used.

We now analyze the social welfare functions to determine the optimal tax. The black line in Figures 5.4-5.6 is the realized social welfare function at a particular tax level, taking into account the decisions of the firm. That is, we determined the technology decisions made by the firm at every tax level, and now plot the resulting optimal social welfare from those decisions. Notice that the black line is discontinuous whenever the firm switches technology choices. A detailed summary of the results is outlined in Table 5.1. When comparing the results of the commitment and no commitment case at each value of $\epsilon$, 'favourable' results for the regulator are shown in green. The regulator is indifferent to the price and technology choices of the firm, and is only interested in the social welfare (firm profit, environmental impact, and consumer surplus) derived from the firm's choices. A lower tax and environmental impact, and a higher profit, consumer surplus, and social welfare are considered favourable for the regulator.

Starting with Example 1(a), low regulator concern for the environment, the social welfare function is the solid black line in Figure 5.4(a) and 5.4(b) for the case of no commitment and commitment, respectively. The optimal tax for each scenario is the tax that results in the largest value of the corresponding social welfare function. We find that the optimal tax is $t^{*}=0$ and $t^{*}=0.1069$ for the case of no regulator commitment and commitment, respectively; with the commitment case yielding a higher social welfare. The results of the no commitment case are in line with the findings of Krass et al. (2013), who also find that when the regulator is not too concerned with the environment, the optimal tax will be zero and the firm will choose the dirty technology. We find that in the case of commitment, the regulator chooses a higher tax that results in a lower environmental impact but also lower firm profits and consumer surplus (more detailed results outlined in Table 5.1). Importantly, the social welfare is higher in this case. In summary, when the government concern for the environment is low, the firm is better off in the no commitment case but the overall social welfare is higher in the case of commitment.

Example 1(b) explores the case of moderate environmental concern by the regulator (cf. Figure 5.5(a) and 5.5(b) for the case of no commitment and commitment, respectively). We find that the optimal tax is $t^{*}=\frac{1}{2}$ and $t^{*}=0.1069$ for the case of no regulator commitment and commitment, respectively; with the commitment case yielding a higher social welfare. 
We find that in the commitment case, the regulator obtains a higher social welfare at a lower tax, with higher profits for firms and a higher consumer surplus. However, in the case of no commitment, the environmental impact is lower.

Lastly, Example 1(c) investigates the case of high environmental concern by the regulator (cf. Figure 5.6(a) and 5.6(b) for the case of no commitment and commitment, respectively). We find that the optimal tax in both the commitment and no commitment case is $t=\frac{1}{2}$, yielding the same firm profit, consumer surplus, environmental impact, and social welfare in both cases. When the regulator's concern for the environment is high enough, the commitment policy will not impact the outcomes. This is because when the regulator is highly concerned about the environment, the firm will behave in a more environmentally friendly way, even in the absence of commitment. A higher environmental concern results in a higher tax. Firm profit and environmental impact are decreasing in tax. Thus as the regulator is more concerned about the environment rather than firm profit, the profit lost by increasing the tax will be more than compensated by the utility gained from the decrease in environmental impact. We know that above the critical tax level, the firm will make the same decisions regardless of the commitment policy of the regulator.

Notice that in all three cases, the social welfare of the commitment case is greater than or equal to the social welfare in the case of no commitment, following the results of Proposition 8. Thus the commitment case always leads to just as favourable or more favourable outcomes than the no commitment case, from the perspective of the regulator. However, as is seen in Table 5.1, the firm profit, environmental impact, consumer surplus are not always greater in the case of commitment.

It is important to notice that due to the discontinuous nature of the optimal social welfare function, the optimal tax level is highly sensitive. In other words, small changes to the tax level around the critical tax may have detrimental impacts on the outcomes. We explore this in-depth in the next subsection.

\subsection{Sensitivity of the optimal tax level}

In this section we examine the stability/sensitivity of the optimal tax level. In other words, we examine the outcome if the regulator sets a tax slightly above or below the optimal tax in Examples 1(a)-(c), and compare the outcomes in the cases of no commitment and commitment. This sensitivity analysis may be of use to regulators for a number of reasons. In practice, the optimal tax may be hard to determine, as the regulator would have to 


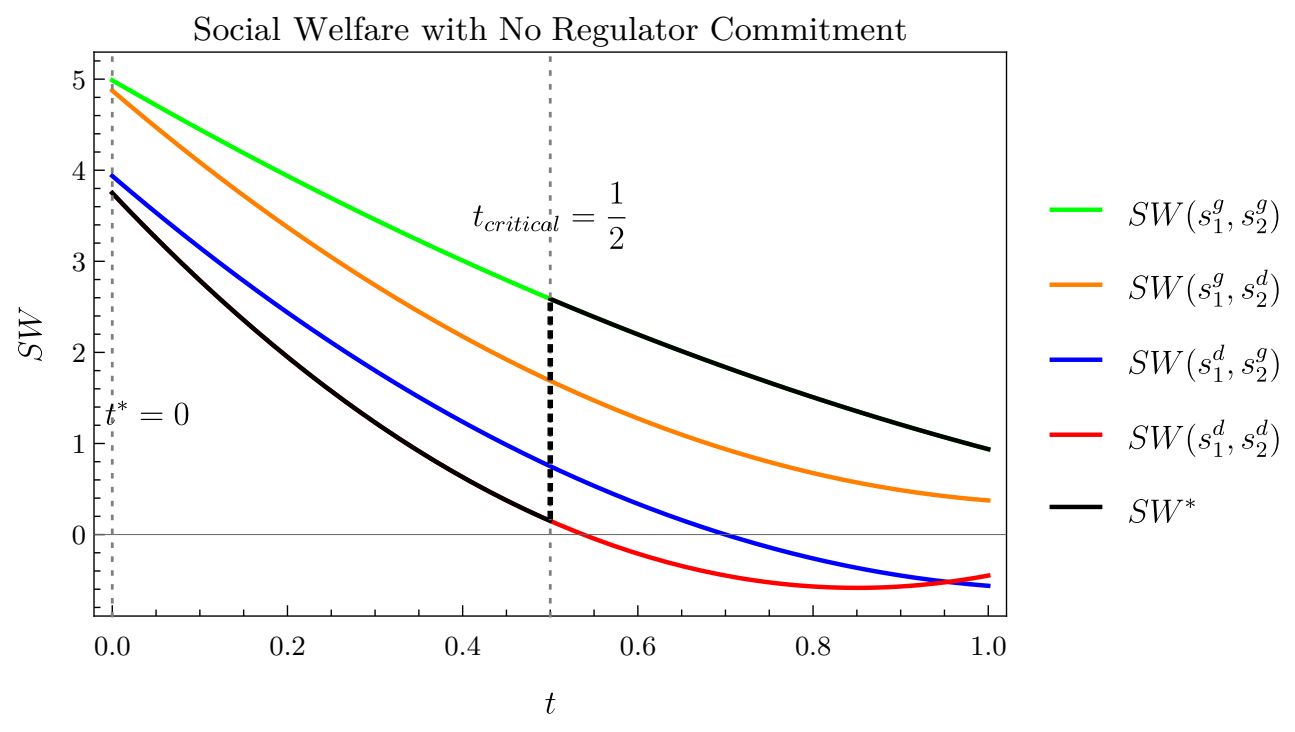

(a) No commitment

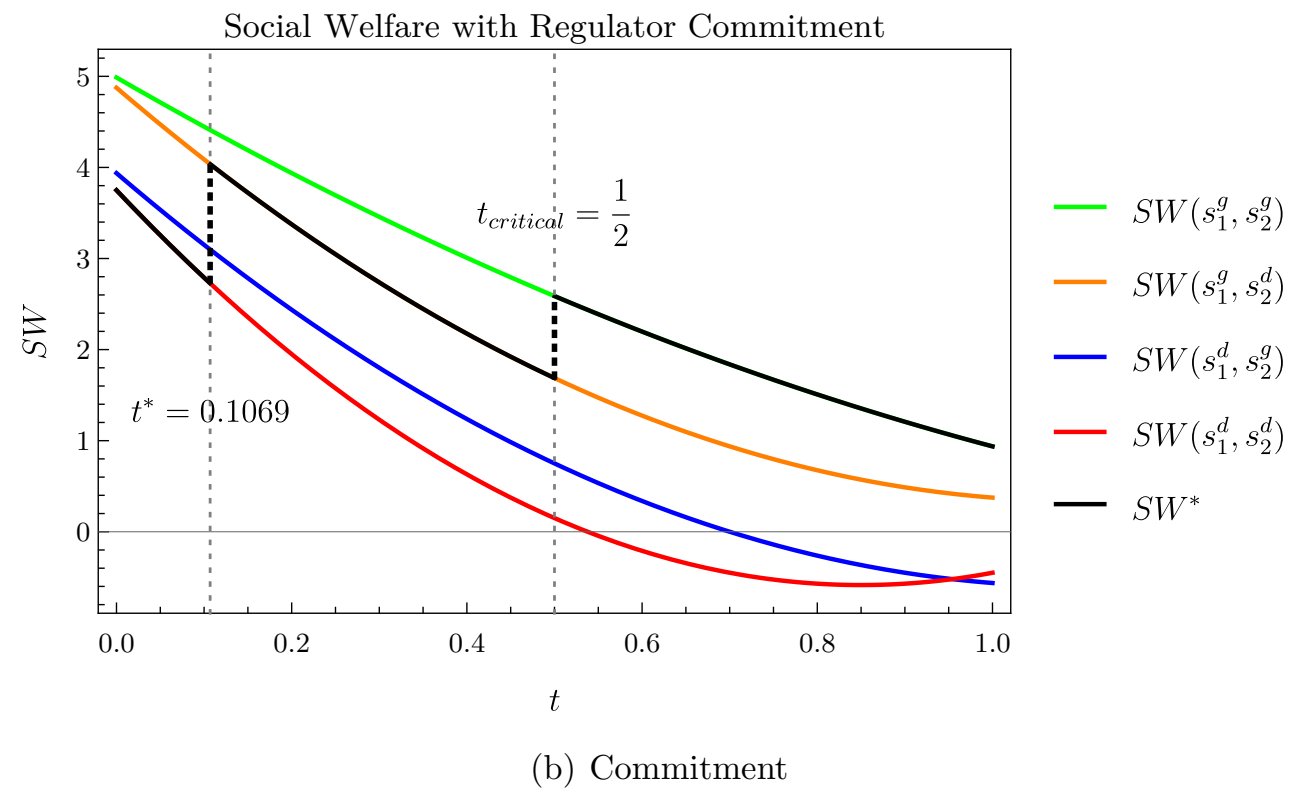

Figure 5.4: Comparing the social welfare in the no commitment and commitment case, with $\epsilon=0.6$ (Example 1(a)) 


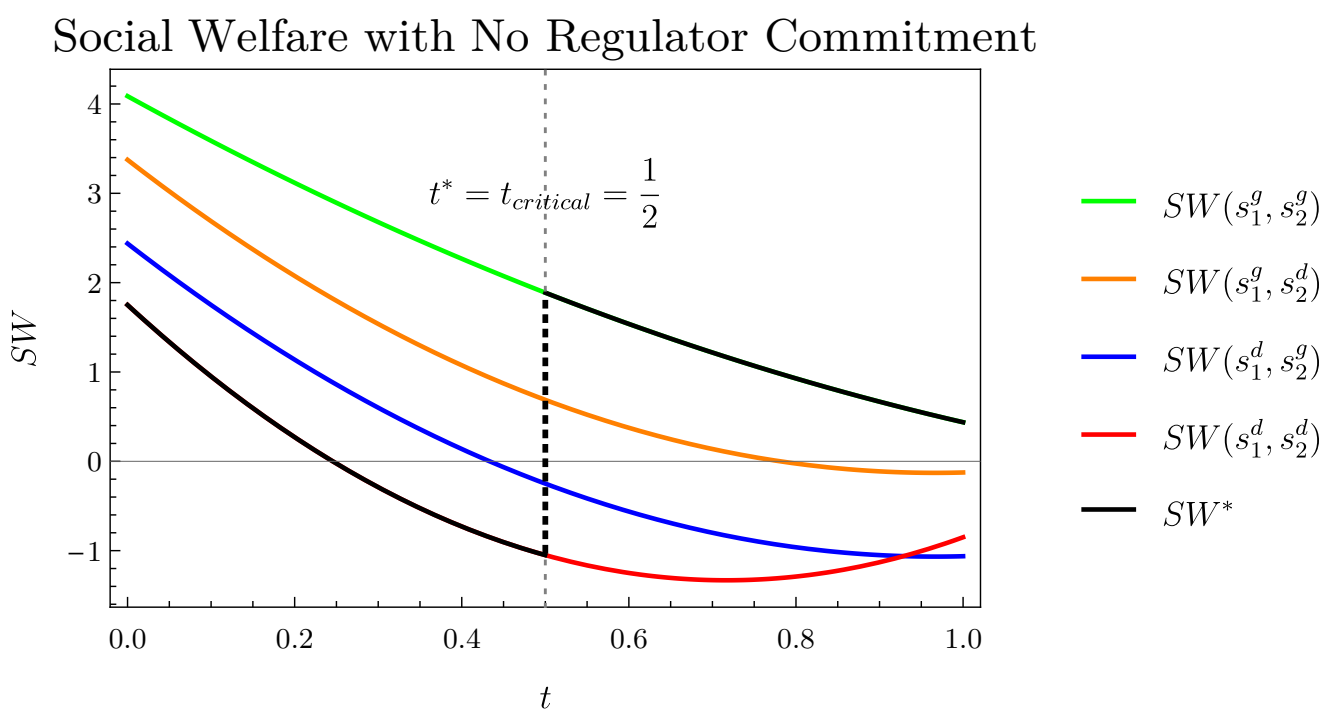

(a) No commitment

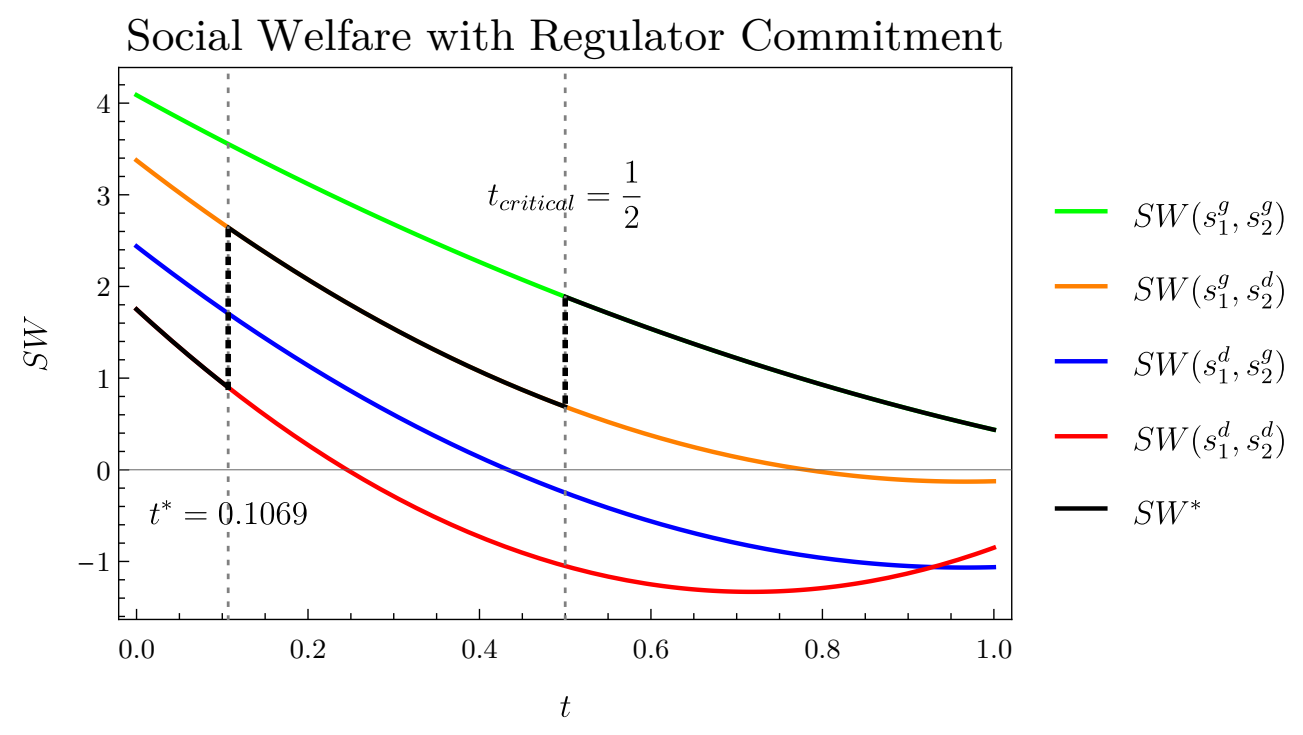

(b) Commitment

Figure 5.5: Comparing the social welfare in the no commitment and commitment case, with $\epsilon=0.8$ (Example 1(b)) 


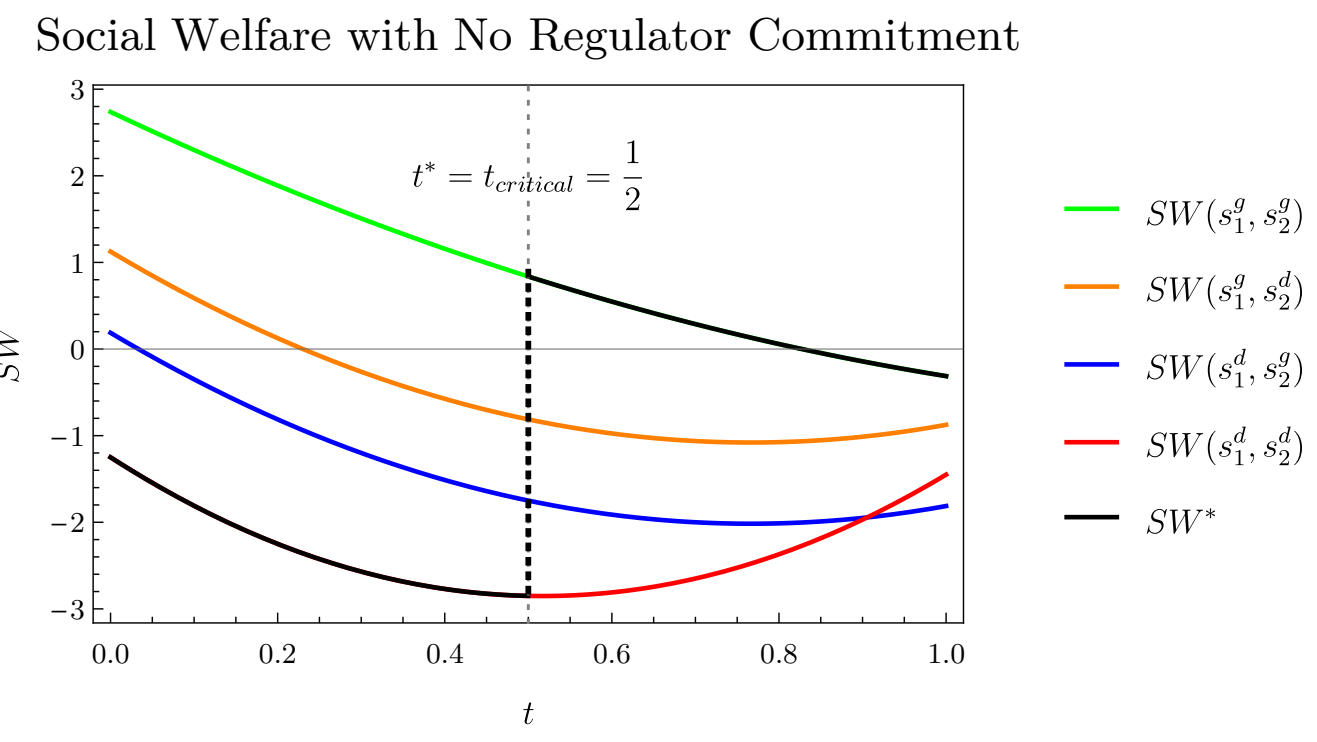

(a) No commitment

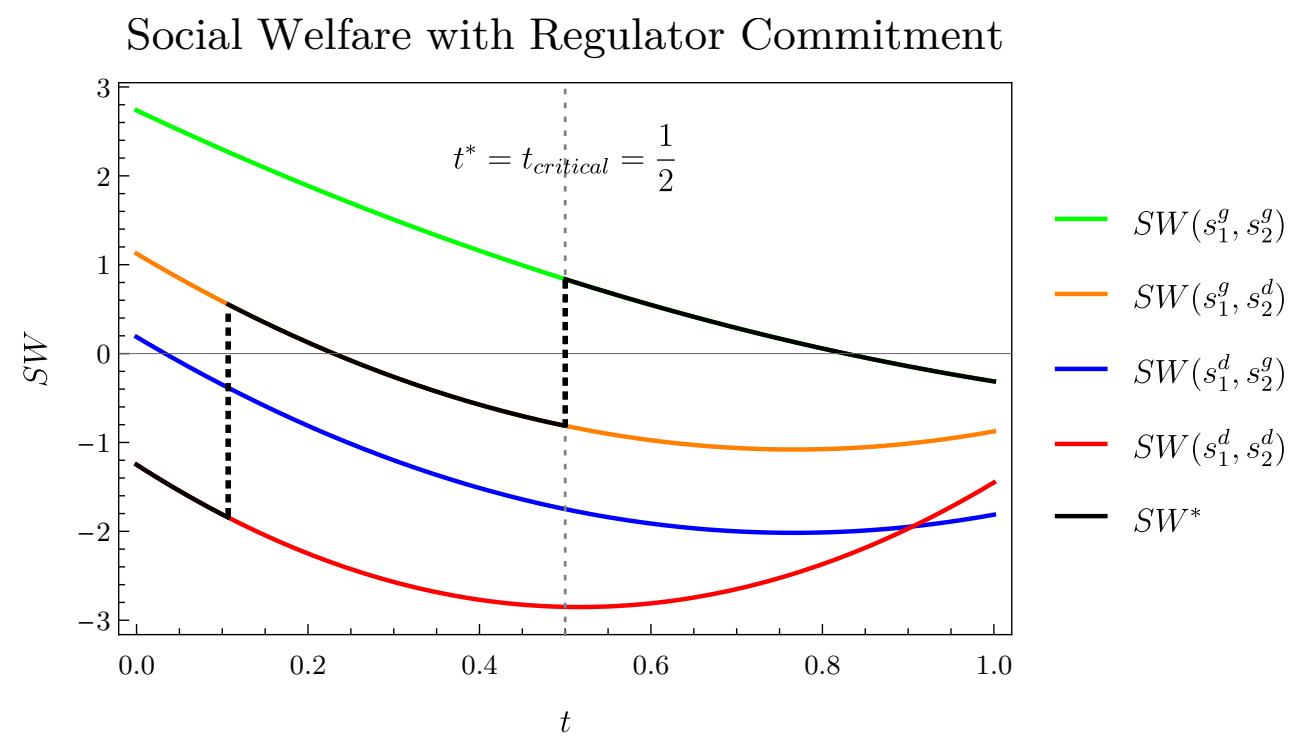

(b) Commitment

Figure 5.6: Comparing the social welfare in the no commitment and commitment case, with $\epsilon=1.1$ (Example 1(c)) 


\begin{tabular}{|c|cc|cc|cc|}
\hline & \multicolumn{2}{|c|}{$\epsilon=0.6$} & \multicolumn{2}{c|}{$\epsilon=0.8$} & \multicolumn{2}{c|}{$\epsilon=1.1$} \\
\hline & $\begin{array}{c}\text { No } \\
\text { commitment }\end{array}$ & Commitment & $\begin{array}{c}\text { No } \\
\text { commitment }\end{array}$ & Commitment & $\begin{array}{c}\text { No } \\
\text { commitment }\end{array}$ & Commitment \\
\hline$p_{1}^{*}$ & 3.000 & 3.500 & 3.500 & 3.500 & 3.500 & 3.500 \\
$p_{2}^{*}$ & 2.500 & 2.750 & 3.250 & 2.750 & 3.250 & 3.250 \\
$s_{1}^{j *}$ & dirty & green & green & green & green & green \\
$s_{2}^{j *}$ & dirty & dirty & green & dirty & green & green \\
$t^{*}$ & 0 & 0.1069 & 0.5000 & 0.1069 & 0.500 & 0.500 \\
\hline$\pi_{\text {Total }}^{*}$ & 6.500 & 5.477 & 3.125 & 5.477 & 3.125 & 3.125 \\
$E I^{*}$ & 6.000 & 4.179 & 2.800 & 5.573 & 3.850 & 3.850 \\
$C S^{*}$ & 3.250 & 2.739 & 1.563 & 2.739 & 1.563 & 1.563 \\
$S W^{*}$ & 3.750 & 4.037 & 1.888 & 2.643 & 0.8380 & 0.8380 \\
\hline
\end{tabular}

Table 5.1: Summary of results at the optimal firm and regulator decisions (more favourable outcomes are shown in green)

estimate the parameter values. Public opinion on carbon taxes, as well as political limitations may also prevent regulators from setting the optimal tax level. Thus, in practice, the regulator may knowingly or unknowingly set sub-optimal taxes. Overall, we find that outcomes of the no commitment case are more sensitive to small changes in the optimal tax than the commitment case. That is, small deviations from the optimal tax result in unfavourable outcomes (such as lower social welfare, firm profit, and consumer surplus, and higher environmental impact). Moreover, these negative impacts tend to be greater in the no commitment case than in the commitment case.

Suppose $\kappa>0$, a very small number such that $\kappa^{2} \approx 0$. Notice that in Examples $1(\mathrm{a})-(\mathrm{c})$, the firm switches technologies at $t=t^{*}-\kappa$, and does not when $t=t^{*}+\kappa$ (see Figures 5.4-5.6). When the firm switches technologies, there are significant impacts on the resulting social welfare, whereas when the firm makes the same technology choice at a slightly higher tax, the changes are negligible. Thus we focus our sensitivity analysis on the case where $t=t^{*}-\kappa$. We now consider the outcomes when the regulator sets a tax $t^{*}-\kappa$, that is, a tax slightly below the optimal tax level.

We consider how this impacts the results of Example 1(b) and Example 1(c), and summarize the results in Table 5.2 and Table 5.3, respectively. We employ the assumption that $\kappa^{2}=0$ in the results of the tables to simplify results. When results are more favourable at $t=t^{*}-\kappa$ the percent change is shown in green, and the percent change is shown in red when the results are less favourable. We do not perform this analysis for example Example 1(a), since the optimal tax in the case of no commitment is zero, so $t^{*}-\kappa$ would 
be negative, and the regulator cannot set a negative tax. In the following analysis, we consider $\kappa=0.001$.

The results of a small change in the optimal tax level in Example 1(b) are summarized in Table 5.2. Starting with the case of commitment, we compare the results of when the regulator sets the optimal tax $t^{*}=0.1069$ to $t=0.1069-\kappa$. We find that by decreasing the optimal tax slightly, the profit and consumer surplus will actually increase, but negligibly so. However, the environmental impact will increase and social welfare will decrease. In the case of no commitment, we compare the results of when the regulator sets the optimal tax $t^{*}=0.5000$ to $t=0.5000-\kappa$. This results in non-negligible decreases in firm profit, consumer surplus, and social welfare, as well as an increase in the environmental impact. When compared to the commitment case: (1) the firm profit decreases by $19.81 \%$ in the no commitment case, while it increases negligibly in the commitment case; (2) the environmental impact increases by $6.550 \%$ more in the commitment case; (3) the consumer surplus decreases by $19.83 \%$ with no commitment, and increases negligibly with commitment; (4) the social welfare decreases by $108.0 \%$ more in the case of no commitment. Thus, the commitment model is less sensitive to the small change in the tax level set by the regulator in every outcome except for the environmental impact. However, we note that the tax level is smaller in the case of commitment, so a higher environmental impact is expected. A direct comparison in the sensitivity of the optimal tax levels between the commitment and no commitment case is more sensible when the optimal taxes are the same, as in Example 1(c).

We now consider a small change in the optimal tax level in Example 1(c), with the results outlined in Table 5.3. In this case, the optimal tax levels are equal in the commitment and no commitment case. That is, if only analyzed at the optimal tax level, the outcomes in the commitment and no commitment cases are the same. However, the behaviour is different between the two cases when we investigate the outcomes at sup-optimal tax levels. A small change in the optimal tax level causes a greater decrease in profit, consumer surplus, and social welfare in the case of no commitment. It also causes a greater increase in environmental impact in the no commitment case. In other words, at $t-\kappa$, the commitment model has more favourable outcomes for firms, consumers, the environment, and the regulator.

These results show that in the commitment case, the optimal tax is less sensitive to small deviations from the optimal tax. This is because of the discontinuous nature of the social welfare function, which arises from the discrete technology choices. In Examples 1(b) and (c), the optimal tax is the critical tax level. At the critical tax level, the firm will choose the green technology in both periods, in both the commitment and no commitment case. A small change in the optimal tax, namely at $t^{*}-\kappa$, prompts a switch to the dirty 


\begin{tabular}{|c|ccc|ccc|}
\hline & \multicolumn{3}{|c|}{ Commitment } & \multicolumn{3}{c|}{ No commitment } \\
\hline & $t=0.1069$ & $t=0.1069-\kappa$ & $\%$ change & $t=0.5000$ & $t=0.5000-\kappa$ & $\%$ change \\
\hline$s_{1}^{j^{*}}$ & green & dirty & - & green & dirty & - \\
$s_{2}^{j^{*}}$ & dirty & dirty & - & green & dirty & - \\
$\pi_{\text {Total }}$ & 5.477 & 5.486 & $0.1670 \%$ & 3.125 & 2.506 & $\mathbf{1 9 . 8 1 \%}$ \\
$E I$ & 5.573 & 7.322 & $31.39 \%$ & 3.850 & 4.806 & $\mathbf{2 4 . 8 4 \%}$ \\
$C S$ & 2.739 & 2.743 & $0.1304 \%$ & 1.563 & 1.253 & $\mathbf{1 9 . 8 3 \%}$ \\
$S W$ & 2.643 & 0.9065 & $\mathbf{6 5 . 7 0 \%}$ & 0.838 & -1.047 & $\mathbf{2 2 5 . 0 \%}$ \\
\hline
\end{tabular}

Table 5.2: Summary of Results, $\epsilon=0.8$, just below the optimal tax, $t^{*}-\kappa$, where $\kappa=0.001$

\begin{tabular}{|c|ccc|ccc|}
\hline & \multicolumn{3}{|c|}{ Commitment } & \multicolumn{3}{c|}{ No commitment } \\
\hline & $t=0.5000$ & $t=0.5000-\kappa$ & $\%$ Change & $t=0.5000$ & $t=0.5000-\kappa$ & $\%$ Change \\
\hline$s_{1}^{j^{*}}$ & green & green & - & green & dirty & - \\
$s_{2}^{j^{*}}$ & green & dirty & - & green & dirty & - \\
$\pi_{\text {Total }}$ & 3.125 & 3.130 & $0.1600 \%$ & 3.125 & 2.506 & $\mathbf{1 9 . 8 1 \%}$ \\
$E I$ & 2.800 & 5.506 & $96.63 \%$ & 2.800 & 6.609 & $\mathbf{1 3 6 . 0 \%}$ \\
$C S$ & 1.563 & 1.566 & $0.1599 \%$ & 1.563 & 1.253 & $\mathbf{1 9 . 8 3 \%}$ \\
$S W$ & 1.888 & -0.8105 & $\mathbf{1 4 2 . 9 \%}$ & 1.888 & -2.850 & $\mathbf{2 5 0 . 9 \%}$ \\
\hline
\end{tabular}

Table 5.3: Summary of Results, $\epsilon=1.1$, just below the optimal tax, $t^{*}-\kappa$, where $\kappa=0.001$ 
technology in both periods in the case of no commitment, whereas with commitment, the firm will still choose the green technology in the first period, and switch to the dirty technology in the second period. Recall from Section 4.1 in the case of no commitment, the firm either chooses the green technology in both periods (at or above the critical tax level), or the dirty technology in both periods (below the critical tax level). However, in the case of commitment, the firm may also choose the strategy $\left(s_{1}^{g}, s_{2}^{d}\right)$. Thus, there is an intermediary strategy between $\left(s_{1}^{d}, s_{2}^{d}\right)$ and $\left(s_{1}^{g}, s_{2}^{g}\right)$ in the commitment case. In the case of no commitment, the firm switches from from $\left(s_{1}^{g}, s_{2}^{g}\right)$ to $\left(s_{1}^{d}, s_{2}^{d}\right)$ when there is a small decrease in the optimal tax level. In contrast, when there is commitment, the firm will first switch to $\left(s_{1}^{g}, s_{2}^{d}\right)$ with small decreases in the optimal tax, then to $\left(s_{1}^{d}, s_{2}^{d}\right)$ only after much larger decreases to the optimal tax level. This makes the commitment case more robust less sensitive - to small changes in the tax set by the regulator. 


\section{Chapter 6}

\section{Discussion}

We now discuss the theoretical and managerial insights of our work.

\subsection{Theoretical Insights}

To the best of our knowledge, we are the first to propose a two-period carbon tax model that provides a direct comparison between a commitment and a no commitment policy. The current literature does address uncertainty in carbon tax policies, but as Section 2 discusses in detail, we are the first to assume a true baseline of no regulator commitment. That is, a lack of regulator commitment in the literature is modelled by a tax policy following a probability distribution. In our model, the firm has no information about the tax level that will be set by the regulator in the second period, and thus behaves myopically.

A natural extension of this work may be to consider that the firm has a continuum of technologies to choose from. However, we did not find this modelling consideration analytically tractable. The existence of multiple, linked periods in our model makes analysis difficult. Modellers who wish to incorporate a continuum of technology choices should investigate simplifying other areas of the model, such as the demand or cost functions, to obtain analytically tractable solutions. For example, modellers may explore the impact of using a negative exponential demand function rather than a linear demand function.

Although we show that the optimal social welfare is always greater or equal in the case of commitment at the optimal tax level, the environmental impact is not always lower (Example 1(b)). This is because the optimal tax levels may differ under the commitment and no commitment policies. In our model, the demand is tied to the firm's technology 
choice, and the first period technology choice is linked to the second period demand. The overall emissions of the firm are not linked between the two periods. Thus, introducing regulator commitment may not necessarily lower overall pollution emissions, but will instead make the use of the green technology in the first period more likely. Modellers who wish to focus more on total emissions rather than technology choices made by the firm should link the demand between periods by total emissions. However, this may be a less realistic assumption - as it would require consumers to have information about overall environmental impact of a firm rather than just the production process/technology used.

The assumption that consumers are solely concerned with total emissions would not extend to the case of multiple firms. As a thought experiment, suppose there is one firm that produces 100 products, but they use a green production process that emits $1 \mathrm{~kg}$ of $\mathrm{CO}_{2}$ per product, which results in $100 \mathrm{~kg}$ of $\mathrm{CO}_{2}$ in total emissions. Now consider 10 firms, who each produce 10 products, but they use a dirty production process that leads to $10 \mathrm{~kg}$ of $\mathrm{CO}_{2}$ per product, which results in $100 \mathrm{~kg}$ of $\mathrm{CO}_{2}$ per firm, or $1000 \mathrm{~kg}$ of $\mathrm{CO}_{2}$ in total. With a single green firm, 100 products are produced with $100 \mathrm{~kg}$ of $\mathrm{CO}_{2}$ in total emissions, while with 10 dirty firms, 100 products are produced with $1000 \mathrm{~kg}$ of $\mathrm{CO}_{2}$ in total emissions. Surely the more environmentally-friendly way to produce the 100 products is through the single green firm. However, if consumers are only concerned about total emissions of the firm and not emissions per product (i.e. technology choice in our model), then consumers will view the green and dirty firms in this thought experiment as equally good for the environment, since they both emit $100 \mathrm{~kg}$ of $\mathrm{CO}_{2}$ in total. The assumption that consumers are only concerned about total emissions may be sufficient in the case of a single monopolistic firm, but it may not be valid in practice. Our results, along with this example, show that in future work, it may be beneficial to link the demand between periods by total emissions and technology choice, not one or the other.

Regulators may also encourage firms to prioritize total emissions and technology choice by taxing firms on their total emissions, as we do in our model, and providing subsidies to firms who use greener technologies. Krass et al. (2013) consider both subsidies and taxes, but not with regulator commitment. In our model, that may look like regulators increasing or decreasing $\gamma$, the pollution sensitivity of the variable cost. The results of using $\gamma$ as a mechanism of emissions regulation are unknown, and should be explored in future models considering regulator commitment. 


\subsection{Managerial Insights}

Our work emphasizes the value of carbon tax policy commitment on social welfare. We show that the optimal social welfare obtained by the regulator is always greater when the regulator is willing to commit to a two-period tax at the beginning, rather than announcing their tax at the beginning of each of the two periods (Proposition 8). Thus, it is in the regulator's best interest to commit in order to obtain more favourable societal outcomes.

Although it is noteworthy that the optimal social welfare is greater in the commitment case, Proposition 7 is a much stronger result. It states that the social welfare is greater in the commitment case when compared to the no commitment case at every tax level (Proposition 7). This is a stronger result because, for a variety of reasons, the regulator may not be able to set the optimal tax. Practically speaking, the regulator may not be able to accurately estimate all the model parameters, resulting in the regulator unintentionally setting a sub-optimal tax. Political feasibility, public opinion, and the socioeconomic makeup of a regulator's constituents are just a few of the multitude of factors that may require the firm to set sub-optimal tax levels. Our model shows that it is always in the regulator's best interest to commit, even when they are not selecting the optimal tax.

We find that regulator commitment is not always beneficial for firms, as we see in Example 1(a) that the firm can obtain a higher profit at the optimal tax level in the case of no commitment. This occurs when the regulator's concern for the environment is low. It is important to note that result arises from the fact that the optimal tax is higher in the commitment case. Lemma 4.3.1 states that the profit is always higher in the case of regulator commitment, when the commitment and no commitment case is compared at the same tax level. It makes sense that low regulator concern for the environment leads to no tax, and this would be beneficial to firms as profit decreases with tax level.

In the numerical examples we show that there are cases in which the regulator may achieve a higher social welfare at a lower tax in the commitment case (Example 1(b), moderate regulator commitment). It is known empirically that people have strong objections to higher carbon taxes, potentially making lower taxes more politically feasible (Carattini et al., 2017; Gevrek and Uyduranoglu, 2015; Sælen and Kallbekken, 2011). The regulator is better off as this yields a higher social welfare at a lower tax, while the firm also achieves a higher profit. Thus it is beneficial to both players in the game for the regulator to commit.

The numerical experiments, particularly Example 1(c) shows that when the regulator has a high enough concern for the environment, the optimal tax and social welfare are the same in both the commitment and no commitment cases. We show that the firm will make the same decision with or without regulator commitment when the optimal tax is at or 
above the critical tax level. Since the environmental impact decreases with tax level, when the regulator's concern for the environment grows the optimal tax may increase. Once the optimal tax reaches or exceeds the critical tax level, we know that the optimal outcome in the commitment or no commitment case will be the same. However, we show in the sensitivity analysis in Section 5.2 that although the optimal outcomes are equivalent, the sub-optimal outcomes are more favourable in the case of commitment: for firms, regulators, the environment, and for consumers. Thus, a high concern for the environment cannot entirely 'replace' regulator commitment if the regulator needs the political flexibility to set sub-optimal tax levels.

Proposition 2 provides insights to regulators on how to lower the critical tax level, that is, the tax at which the firm switches their technology choice. In the case of no regulator commitment, the critical tax represents the tax level at which the firm switches from choosing the dirty technology in both periods to choosing the green technology in both periods. In the case of regulator commitment, it represents the tax level at which the firm chooses the green technology in both periods, before this tax, the firm will either choose the dirty technology in both periods or the green technology in the first period and the dirty technology in the second period. The critical tax increases with the pollution sensitivity of variable cost. That is, when dirty technologies are much cheaper than green technologies, the critical tax increases. Regulators may subsidize green technologies to lower the critical tax level, if high taxes are politically unfavourable. Regulators may also invest in research and development in green technologies in order to lower the pollution sensitivity of the variable cost. The critical tax also decreases with pollution sensitivity of demand. To lower the critical tax level, regulators may focus on increasing consumers' care for the environment, through education on the negative outcomes of climate change, for example. In addition, regulators may require firms to be more transparent about their production process to consumers, so consumers are able to make more informed decisions regarding the 'greenness' of a product they are purchasing. 


\section{Chapter 7}

\section{Conclusion}

In this article, we investigate the impact of carbon tax policy commitment on firm profits, optimal tax levels, and overall social welfare. We consider a two-period interaction between the regulator and the firm. More specifically, we consider a monopolistic, profit-maximizing firm that sets the product price and chooses between two production processes that vary in emissions output per unit produced at the beginning of each period. The regulator sets a carbon tax at the beginning of each period to maximize social welfare. We examine two cases: the case of commitment where the regulator sets one tax for both periods, allowing the firm to be forward-looking, and the case of no commitment, where the government sets the tax at the beginning of each period, which results in the firm behaving myopically. This direct comparison gives policy makers insights into the importance of carbon tax policy commitment.

We show that regulators can achieve a greater social welfare under the commitment policy compared to the no commitment policy, and in certain cases, at a lower optimal tax level. In addition, firm profit and consumer surplus are always greater, and the environmental impact is lower under the commitment policy when compared to the no commitment policy at a particular tax level. Another key insight from this work is that the outcomes of the commitment policy are less sensitive to small decreases in the optimal tax level, which is of interest to regulators who may have to resort to sub-optimal tax levels for a variety of reasons.

An immediate extension of this work would be to consider technology switching costs. In this work, the technology costs differ, but only through the variable production cost. This is an oversimplification as, in reality, changing the production process to a greener or dirtier technology may be costly. No fixed costs related to changing technology implies, for 
example, no costs associated with the installation of new equipment. The results with this addition will likely be nontrivial. Krass et al. (2013), considering the impact of a carbon tax on firm technology choice, determine that the difference in fixed cost across different technologies results in non-monotone behaviour by firms, that is, higher tax levels may initially induce the use of green technologies, but larger increases may cause a switch back to dirty technologies.

Another future research direction could include the consideration of firms being involved in contracts with other members of their supply chain, binding them to a particular technology choice for the duration of the contract. The literature suggests this is a relevant and important modelling aspect. For example, Gao and Zheng (2017) consider the firm to be the Stackelberg leader, because firms enter into long-term investments regarding their production processes that determine their emissions output, while policies are often uncertain in the long term. However, in these works, the impact of policy commitment is not considered. Thus, comparing commitment and no commitment policies while firms are able to enter into technology contracts of varying duration and costs may provide additional needed insights.

A limitation of this work is that many regulator's use the revenue generated from environmental tax policies to fund green projects. For example, the regulator could use the first period tax revenue to compensate firm's switching to the green technology in the second period. Due to the structure of the cost function, including a tax revenue term in the social welfare function would cancel out the tax the firm pays to the regulator (see Section 3.2), and thus our current model cannot support this extension. The exploration of alternative cost functions warrant future investigation in order to account for tax revenue in the social welfare function. 


\section{References}

Alizamir, S., F. de Véricourt, and P. Sun (2016). Efficient feed-in-tariff policies for renewable energy technologies. Operations Research 64(1), 52-66.

Barnett, A. H. (1980). The pigouvian tax rule under monopoly. The American Economic Review 70 (5), 1037-1041.

Barradale, M. J. (2014). Investment under uncertain climate policy: A practitioners' perspective on carbon risk. Energy policy 69, 520-535.

Bi, G., M. Jin, L. Ling, and F. Yang (2017). Environmental subsidy and the choice of green technology in the presence of green consumers. Annals of Operations Research 255(1-2), $547-568$.

Bian, J. and X. Zhao (2020). Tax or subsidy? an analysis of environmental policies in supply chains with retail competition. European Journal of Operational Research 283(3), 901-914.

Carattini, S., A. Baranzini, P. Thalmann, F. Varone, and F. Vöhringer (2017). Green taxes in a post-paris world: are millions of nays inevitable? Environmental and Resource Economics 68(1), 97-128.

Chemama, J., M. C. Cohen, R. Lobel, and G. Perakis (2019). Consumer subsidies with a strategic supplier: Commitment vs. flexibility. Management Science 65(2), 681-713.

Di Lorenzo, G., P. Pilidis, J. Witton, and D. Probert (2012). Monte-carlo simulation of investment integrity and value for power-plants with carbon-capture. Applied Energy 98, $467-478$.

Drake, D. F. (2018). Carbon tariffs: Effects in settings with technology choice and foreign production cost advantage. Manufacturing \& Service Operations Management 20(4), 667-686. 
Drake, D. F., P. R. Kleindorfer, and L. N. Van Wassenhove (2016). Technology choice and capacity portfolios under emissions regulation. Production and Operations Management 25(6), 1006-1025.

Drake, D. F. and S. Spinler (2013). Om forum-sustainable operations management: an enduring stream or a passing fancy? Manufacturing $\&$ Service Operations Management 15(4), 689-700.

Epp, C. (2020, Mar). Oil price plunge puts alberta budget into question.

Fan, L., B. F. Hobbs, and C. S. Norman (2010). Risk aversion and co2 regulatory uncertainty in power generation investment: Policy and modeling implications. Journal of Environmental Economics and Management 60(3), 193-208.

Gao, X. and H. Zheng (2017). Environmental concerns, environmental policy and green investment. International Journal of Environmental Research and Public Health 14(12), 1570 .

Gevrek, Z. E. and A. Uyduranoglu (2015). Public preferences for carbon tax attributes. Ecological Economics 118, 186-197.

Gong, X. and S. X. Zhou (2013). Optimal production planning with emissions trading. Operations Research 61(4), 908-924.

Government of Alberta (2020). Budget 2020: Fiscal plan 2020-23. https: //open.alberta.ca/dataset/05bd4008-c8e3-4c84-949e-cc18170bc7f7/ resource/79caa22e-e417-44bd-8cac-64d7bb045509/download/ budget-2020-fiscal-plan-2020-23.pdf.

Jeffords, S. (2018, Jul). Cancelling prince edward county wind project could cost over $\$ 100 \mathrm{~m}$, company warns. https://globalnews.ca/news/4325378/ prince-edward-county-wind-project-cancellation/.

Jin, M., X. Shi, A. Emrouznejad, and F. Yang (2018). Determining the optimal carbon tax rate based on data envelopment analysis. Journal of Cleaner Production 172, 900-908.

Krass, D., T. Nedorezov, and A. Ovchinnikov (2013). Environmental taxes and the choice of green technology. Production and operations management 22(5), 1035-1055.

Lee, H. C. B., J. M. Cruz, and R. Shankar (2018). Corporate social responsibility (csr) issues in supply chain competition: Should greenwashing be regulated? Decision Sciences $49(6), 1088-1115$. 
Lin, H., S. Zeng, L. Wang, H. Zou, and H. Ma (2016). How does environmental irresponsibility impair corporate reputation? a multi-method investigation. Corporate Social Responsibility and Environmental Management 23(6), 413-423.

Marshall, A. (2009). Principles of economics: unabridged eighth edition. Cosimo, Inc.

Mazur, A. (2019, Jul). Ontario to compensate white pines wind turbine developers for cancelled contract. https://globalnews.ca/news/5471632/ ontario-white-pines-wind-turbine-cancelled/.

McCarthy, S. (2018, Jul). Cancellation of german-owned ontario wind project prompts warning from berlin. https://www.theglobeandmail.com/business/ article-cancellation-of-german-owned-ontario-wind-project-prompts-warning-from/.

Mohr, L. A. and D. J. Webb (2005). The effects of corporate social responsibility and price on consumer responses. Journal of consumer affairs 39(1), 121-147.

Murray, B. and N. Rivers (2015). British columbia's revenue-neutral carbon tax: A review of the latest "grand experiment" in environmental policy. Energy Policy 86, 674-683.

Reedman, L., P. Graham, and P. Coombes (2006). Using a real-options approach to model technology adoption under carbon price uncertainty: an application to the australian electricity generation sector. Economic Record 82, S64-S73.

Requate, T. (2006). Environmental policy under imperfect competition. The international yearbook of environmental and resource economics 2007, 120-207.

Romano, T. and E. Fumagalli (2018). Greening the power generation sector: Understanding the role of uncertainty. Renewable and Sustainable Energy Reviews 91, 272-286.

Saberi, S., J. M. Cruz, J. Sarkis, and A. Nagurney (2018). A competitive multiperiod supply chain network model with freight carriers and green technology investment option. European Journal of Operational Research 266 (3), 934-949.

Sælen, H. and S. Kallbekken (2011). A choice experiment on fuel taxation and earmarking in norway. Ecological Economics 70(11), 2181-2190.

Shen, B., C. Zhu, Q. Li, and X. Wang (2020). Green technology adoption in textiles and apparel supply chains with environmental taxes. International Journal of Production Research, 1-18. 
Sinha, A., P. Malo, A. Frantsev, and K. Deb (2013). Multi-objective stackelberg game between a regulating authority and a mining company: A case study in environmental economics. In 2013 IEEE congress on evolutionary computation, pp. 478-485. IEEE.

Wolfram Research Inc. (2019). Mathematica, Version 12.1. Champaign, IL, 2020; https: //www.wolfram.com/mathematica.

Yamazaki, A. (2017). Jobs and climate policy: Evidence from british columbia's revenueneutral carbon tax. Journal of Environmental Economics and Management 83, 197-216.

Yatchew, A. and A. Baziliauskas (2011). Ontario feed-in-tariff programs. Energy Policy $39(7), 3885-3893$.

Yenipazarli, A. and A. Vakharia (2015). Pricing, market coverage and capacity: Can green and brown products co-exist? European Journal of Operational Research 242(1), 304-315.

Yu, M., J. M. Cruz, et al. (2019). The sustainable supply chain network competition with environmental tax policies. International Journal of Production Economics 217, $218-231$.

Yu, Y., X. Han, and G. Hu (2016). Optimal production for manufacturers considering consumer environmental awareness and green subsidies. International Journal of Production Economics 182, 397-408.

Yuyin, Y. and L. Jinxi (2018). The effect of governmental policies of carbon taxes and energy-saving subsidies on enterprise decisions in a two-echelon supply chain. Journal of Cleaner Production 181, 675-691. 


\section{APPENDICES}

The following are the conditions under which $\pi_{\text {Total }}\left(s_{1}^{g}, s_{2}^{d}\right) \geq \pi_{\text {Total }}\left(s_{1}^{d}, s_{2}^{d}\right)$ in the commitment case, below the critical tax level. This result is used to prove Lemma 4.3.2.

$$
\begin{aligned}
& \epsilon>0 \wedge F>0 \wedge\left(\left(1<s^{d}<\sqrt{3}+1 \wedge\left(\left(s^{g}=1 \wedge \gamma>0 \wedge \alpha>0 \wedge\left(\left(0<\beta \leq \frac{\alpha \gamma}{2 s^{d}}\right.\right.\right.\right.\right.\right. \\
& \left.\wedge \frac{\alpha \gamma-2 \beta s^{d}}{\alpha s^{d}}<t \leq \frac{\alpha \gamma-\beta s^{d}}{\alpha s^{d}} \wedge a \geq x\right) \vee\left(\frac{\alpha \gamma}{2 s^{d}}<\beta<\frac{\alpha \gamma}{s^{d}} \wedge 0<t \leq \frac{\alpha \gamma-\beta s^{d}}{\alpha s^{d}}\right. \\
& \wedge a \geq x))) \vee\left(1<s^{g}<s^{d} \wedge \gamma>0 \wedge \alpha>0 \wedge\left(\left(0<\beta<\frac{\alpha \gamma}{2 s^{d} s^{g}}\right.\right.\right. \\
& \left.\wedge \frac{\alpha \gamma-2 \beta s^{d} s^{g}}{\alpha s^{d} s^{g}}<t \leq \frac{\alpha \gamma-\beta s^{d} s^{g}}{\alpha s^{d} s^{g}} \wedge a \geq y\right) \\
& \left.\left.\left.\left.\vee\left(\frac{\alpha \gamma}{2 s^{d} s^{g}} \leq \beta<\frac{\alpha \gamma}{s^{d} s^{g}} \wedge 0<t \leq \frac{\alpha \gamma-\beta s^{d} s^{g}}{\alpha s^{d} s^{g}} \wedge a \geq y\right)\right)\right)\right)\right) \\
& \vee\left(s^{d} \geq \sqrt{3}+1 \wedge 1 \leq s^{g}<s^{d} \wedge \gamma>0 \wedge \alpha>0 \wedge\left(\left(0<\beta<\frac{\alpha \gamma}{2 s^{d} s^{g}}\right.\right.\right. \\
& \left.\wedge \frac{\alpha \gamma-2 \beta s^{d} s^{g}}{\alpha s^{d} s^{g}}<t \leq \frac{\alpha \gamma-\beta s^{d} s^{g}}{\alpha s^{d} s^{g}} \wedge a \geq y\right) \\
& \left.\left.\left.\vee\left(\frac{\alpha \gamma}{2 s^{d} s^{g}} \leq \beta<\frac{\alpha \gamma}{s^{d} s^{g}} \wedge 0<t \leq \frac{\alpha \gamma-\beta s^{d} s^{g}}{\alpha s^{d} s^{g}} \wedge a \geq y\right)\right)\right)\right)
\end{aligned}
$$

with $x$ and $y$ as follows: 


$$
\begin{array}{r}
x=\frac{1}{4 \beta s^{d^{2}}+2 \alpha s^{d^{2}} t-2 \alpha \gamma s^{d}}\left(-\alpha^{2} \gamma^{2}+4 \beta^{2} s^{d^{3}}+\alpha^{2} s^{d^{3}} t^{2}+4 \alpha \beta s^{d^{3}} t+2 \beta^{2} s^{d^{2}}+\alpha^{2} s^{d^{2}} t^{2}\right. \\
\left.+2 \alpha \beta s^{d^{2}} t-\alpha^{2} \gamma^{2} s^{d}+2 \alpha \beta \gamma s^{d}\right) \\
y=\frac{1}{4 \beta s^{d^{2}} s^{g 2}+2 \alpha s^{d^{2}} s^{g} t-2 \alpha \gamma s^{d} s^{g}}\left(4 \beta^{2} s^{d^{3}} s^{g 2}+\alpha^{2} s^{d^{3}} s^{g 2} t^{2}+4 \alpha \beta s^{d^{3}} s^{g 2} t\right. \\
\left.+2 \beta^{2} s^{d^{2}} s^{g 3}+\alpha^{2} s^{d^{2}} s^{g 3} t^{2}+2 \alpha \beta s^{d^{2}} s^{g 3} t-\alpha^{2} \gamma^{2} s^{d}+2 \alpha \beta \gamma s^{d} s^{g 2}-\alpha^{2} \gamma^{2} s^{g}\right) .
\end{array}
$$

